\title{
A continuous vertically resolved ozone dataset from the fusion of chemistry climate models with observations using a Bayesian neural network
}

\author{
Matt Amos ${ }^{1,2,3}$, Ushnish Sengupta ${ }^{4}$, Paul J. Young ${ }^{1,3}$, and J. Scott Hosking 5, 6 \\ ${ }^{1}$ Lancaster Environment Centre, Lancaster University, Lancaster, UK \\ ${ }^{2}$ Mathematics and Statistics, Lancaster University, Lancaster, UK \\ ${ }^{3}$ Centre for Excellence in Environmental Data Science, Lancaster University, Lancaster, UK \\ ${ }^{4}$ University of Cambridge, Cambridge, UK \\ ${ }^{5}$ British Antarctic Survey, Cambridge, UK \\ ${ }^{6}$ The Alan Turing Institute, London, UK
}

Correspondence: Matt Amos (m.amos1@lancaster.ac.uk)

Abstract. Continuous historic datasets of vertically resolved stratospheric ozone, support the case for ozone recovery, are necessary for the running of offline models and increase understanding of the impacts of ozone on the wider atmospheric system. Vertically resolved ozone datasets are typically constructed from multiple satellite, sonde and ground-based measurements that do not provide continuous coverage. As a result, several methods have been used to infill these gaps, most commonly relying on regression against observed time series. However, these existing methods either provide low accuracy infilling especially over polar regions, unphysical extrapolation, or an incomplete estimation of uncertainty. To address these methodological shortcomings we used and further developed an infilling framework that fuses observations with output from an ensemble of chemistry-climate models within a Bayesian neural network. We used this deep learning framework to produce a continuous record of vertically resolved ozone with uncertainty estimates. Under rigorous testing the infilling framework extrapolated and interpolated skillfully and maintained realistic interannual variability due to the inclusion of physically and chemically realistic models. This framework and the ozone dataset it produced, enables a more thorough investigation of vertically resolved trends throughout the atmosphere.

\section{Introduction}

Ozone in the upper troposphere and stratosphere is monitored predominantly by ozonesondes (e.g., Witte et al., 2017), satellites (e.g., Tegtmeier et al., 2013) and ground based instruments (e.g., Fioletov et al., 2008). Vertically resolved ozone datasets combining measurements from multiple instruments (e.g., Miller et al., 2002; Ball et al., 2017) are regularly used to investigate ozone trends throughout the atmosphere, including the monitoring of ozone recovery in accordance with the Montreal protocol (Chipperfield et al., 2017; WMO, 2018; Ball et al., 2018), and processes such as the impacts of changing ozone concentrations 
on the atmospheric system, the Brewer Dobson circulation (Polvani et al., 2018) and surface climate (Ivy et al., 2017). In determining ozone recovery it is especially useful to use vertically resolved datasets rather than the total ozone column, as the latter can show ozone recovery when in fact depletion in the lower stratosphere might be disguised by increasing tropospheric ozone (Gaudel et al., 2018; Ball et al., 2018).

Gaps are present in these datasets, originating from gaps in the records of individual instruments, due to the finite lifetimes of instruments, difficulty of measuring during polar night (Bowman and Krueger, 1985; Randel and Wu, 1999) as well as funding concerns, leading to an incomplete picture of atmospheric ozone that is particularly prevalent over polar regions (Bodeker et al., 2020). Several statistical infilling methods have been developed to address these observational gaps creating spatially and temporally complete ozone datasets (e.g., Bodeker et al., 2013; Davis et al., 2016) for use as continuous climatologies and for the running of climate models which do not simulate chemistry. These data-driven statistical infilling approaches are comparatively simple and are not well suited to infilling regions of sparse observations because they lack the physical and chemical understanding of the system in the way that chemistry-climate models do not. Here, we describe and demonstrate a new methodology to produce a spatially and temporally continuous vertically resolved ozone dataset. We use a Bayesian neural network as described by Sengupta et al. (2020) to fuse together our best physical and chemical understanding of the chemistryclimate system, represented by chemistry-climate models, with discontinuous observations to construct an assimilated product of vertically resolved ozone.

Continuous ozone datasets, such as those of Randel and Wu (2007), Bodeker Scientific (Bodeker et al., 2013) and SWOOSH (Davis et al., 2016) are generated from statistical models fitted to observations. These observational datasets themselves are constructed from multiple satellite observations, accounting for satellite drift and applying bias corrections, often further supplemented by the addition of ozonesondes or ground based measurements. Satellite measurements of ozone are typically from instruments such as the total ozone mapping spectrometer (TOMS) which measures total column ozone from backscattered UV radiation (Heath et al., 1975), or limb sounders that measure across an atmospheric section providing vertically resolved ozone concentrations (Froidevaux et al., 2008). These satellite measurements are often limited in their coverage, both spatially, particularly over the poles as solar occultation limb sounders require sunlight absent in polar winters, and temporally, by the finite lifetimes of the satellites and their orbits.

Understanding and attributing ozone change and variability is aided by a continuous ozone record that is resolved in time, latitude and height. In addition to the benefits of historic ozone records in monitoring ozone depletion and recovery, ozone records and climatologies are used as offline fields in a variety of climate models that do not compute their own interactive chemistry (Cionni et al., 2011), or for chemical transport models. To this end, there have been several datasets that have produced continuous vertically resolved ozone records by leveraging a variety of infilling techniques. In the following paragraphs we describe infilling techniques used in several of these ozone products, that takes place after the pre-processing, gridding and merging of individual satellite outputs into a single product. These infilling methods represent standard data approaches, which use observational data and supplementary datasets to infer, with some interpolation or regression tool, what the missing values should be. 
Randel and Wu (2007) and Bodeker Scientific (Bodeker et al., 2013) (BSTier1.4) created infilled ozone records by using multi-linear regression to model ozone as a sum of global time series such as the quasi-biennial oscillation and the solar cycle expanded into harmonic components (WMO, 2018). Bodeker et al. (2013) additionally expanded the coefficients of the regression model as Legendre polynomials which implemented latitudinal structure to aid spatial infilling. The advantages of infilling based on regression against observed time series is that the infilling is partially grounded in our observations and knowledge of the physical system. The limitations of such an approach are caused by the linearity of the regression model smoothing the ozone field resulting in an underestimate of interannual variability. Additionally, as with existing filled vertically resolved ozone datasets, sources of uncertainty from both data and infilling method are not fully considered.

In the SWOOSH dataset (Davis et al., 2016), two infilling methods are used. Firstly, gaps near the poles (on regular latitude) are filled by taking data from ozone gridded on an equivalent latitude grid and imputing this data. This method likely underestimates ozone for regions within the polar vortex as any given equivalent latitude will be less than the corresponding geographic latitude. Secondly, data is interpolated for each vertical level using a radial basis function with an inverse multi-quadric function that imputes the mean of the surrounding points adjusted to preference closer points. Where the data is unbounded, such as the poles, interpolation is performed between existing data and the climatological average. This method of interpolation will perform less well over large regions of sparse data and as such the authors comment that the pre-1990 section of the filled dataset should be used with caution. Additionally, bounding the interpolation with the climatology risks not capturing the true trend of the data and as a result the authors recommend not using the filled version for trend analysis.

Another common method used for infilling and data assimilation in atmospheric and climate science is 4-dimensional variational assimilation (4D-Var) (Courtier et al., 1994). This is used in numerical weather prediction to produce historical reanalyses (e.g., Rienecker et al., 2011; Hersbach et al., 2020) where observations are assimilated within the physical constraints of a numerical model. 4D-Var reanalyses are commonly used across environmental disciplines (e.g., Viste et al., 2013; Blunden and Arndt, 2016; Amos et al., 2020) but the method does have limitations. Firstly, it is extremely computationally expensive as the assimilation involves running a numerical model and optimising the model against millions of observations. Secondly, whereas climate projections are typically computed from an ensemble of different models (allowing for variable model performance within the ensemble), in 4D-var the observations are assimilated to a single model which may have inherent biases.

The described infilling methods have their strengths and weaknesses. BSTier1.4 and 4D-Var predictions benefit from an infilling approach grounded in the physical and chemical understanding of the system. However, for BSTier1.4 this is through a simple linear regression, which cannot capture full variability, and for 4D-Var only a single model with high computational expense is used. The infilling from BSTier1.4 and SWOOSH are suitably quick to run but their simplicity results in less accurate infilling, particularly when extrapolating and infilling large regions. Additionally, not all methods consider the complete uncertainty in the infilled predictions.

In this paper we describe a fundamentally different approach to infill historic ozone to produce a continuous vertically resolved record by using archived chemistry-climate models (CCMs), which grounds the infilling method to our understanding of the physical system. These CCMs are weighted, combined and bias corrected within a Bayesian neural network which accurately infills missing data and alongside providing a principled quantification of uncertainty. This approach is also com- 
putationally cheap compared to 4D-Var and, despite being a deep learning algorithm, maintains interpretability such that the predictions can be dissected back to individual model contributions. Section 2 introduces the CCMs, ozone observations and the necessary pre-processing steps to prepare the data for the Bayesian neural network, which is described in section 3, alongside the process of testing and validation. In section 4 we explore the trends and coverage of the infilled ozone dataset and compare it to existing infilled products. Finally, we make concluding remarks in section 5.

\section{Ozone and model data}

Our approach to infilling vertically resolved ozone combines observations from the Bodeker Scientific observational dataset (Bodeker et al., 2013) with an ensemble of chemistry climate models from the Chemistry-Climate Model Initiative (CCMI) (Morgenstern et al., 2017). In this section we summarise the characteristics of these data and detail how we processed them in order to build a machine learning-style dataset to train the Bayesian neural network.

\subsection{Bodeker Scientific vertically resolved ozone}

We used the tier 0 data of vertically resolved ozone from Bodeker scientific (Bodeker et al., 2013) (hereafter referred to as BSTier0) as observations. This dataset combines merged measurements from ozonesondes and satellites onto a coarse resolution grid, following quality checking and screening to remove anomalous values as is described by Bodeker et al. (2013). From BSTier0 we extracted a vertical pressure range of $\{500-0.3 \mathrm{hPa}\}$ and screened values that were less than $1 \mathrm{ppb}$ as the original dataset had negative concentrations caused by satellite retrieval algorithms. This cut-off concentration was chosen because, for the upper troposphere and stratosphere region of interest, concentrations have not been measured to fall below the order of magnitude of $1 \mathrm{ppb}$ even in the ozone deficient tropical tropopause (Newton et al., 2018).

\subsection{CCMI model output}

The CCMI data (Morgenstern et al., 2017) consists of an ensemble of chemistry-climate models (CCMs) that include a detailed description of atmospheric chemistry to better understand the behaviour of compounds whose abundances depend on chemical processes. Similarly to its predecessor initiatives (Eyring et al., 2008; Lamarque et al., 2013), a focus of CCMI is exploring and understanding stratospheric ozone distributions (Morgenstern et al., 2018) and projections (Amos et al., 2020), making this ensemble highly appropriate for our uses.

We used output from the so-called refC1SD scenario (Morgenstern et al., 2018), which are specified dynamics simulations where CCMs are nudged to historic (1980-2010) meteorological conditions (Orbe et al., 2020). Although the nudging was performed differently across the ensemble (Orbe et al., 2020), the simulations represent the models' best efforts at replicating past meteorology and past atmospheric composition. This allows for a straightforward direct comparison between models and observations unlike if the models were free running, in which case we would have to compare trends and climate statistics. From the refC1SD ensemble, we selected 13 simulations of monthly average vertically resolved ozone concentrations from the 
9 models that cover the vertical pressure range $\{500-0.3 \mathrm{hPa}\}$. The output was latitudinally regridded to match the resolution of the observations $\left(5^{\circ}\right)$ and were longitudinally averaged, producing a zonal mean.

\subsection{Making the data machine learning ready}

We performed coordinate mappings and data scaling to both the BSTier0 observations and model output. These steps, common in machine learning (ML) applications, ensure that the data is descriptive of the spatiotemporal domain and allow us to encode our prior understanding of the system into machine learning (ML) models.

After pre-processing, the ozone data both modelled and observed is described by time, latitude and a vertical coordinate. The vertical coordinate air pressure $p$ was mapped using a natural logarithm to $\ln (p)$ to provide a consistently decreasing vertical coordinate which is proportional to height. Latitude $(\theta)$, the second spatial coordinate, is mapped to $\sin (\theta)$. We mapped time $t$ (in this case the number of months since the start of the observations) onto seasonal harmonic terms $(\cos (2 \pi t / 12)$ and $\sin (2 \pi t / 12))$ as well as keeping $t$ as a continuous time coordinate. The seasonal mapping requires two elements to ensure continuity over the first and last months so that the data reflects that January and December are adjacent months.

Subsequent to the mapping, the coordinates were min-max scaled to between -1 and 1 , which ensures that all coordinates are initially treated as equally important. Additionally, the model predictions and observations of ozone concentrations were scaled with a natural logarithm, before being min-max scaled such that the observations are between -1 and 1 . The motivation for the log scaling is twofold. Firstly, the log transformation means that ML tools can learn evenly across a domain where ozone concentrations span multiple orders of magnitude. Without performing this log scaling, the learning efforts would be focussed in the regions of larger concentrations $(\sim 1 \mathrm{ppm})$ because these would be the regions in which an ML model could more easily minimise the absolute error (the difference between the observations and the prediction). Secondly, as negative concentrations are unrealistic, the log scaling constrains the prediction to be strictly positive.

To test the predictive capability of the Bayesian neural network, particularly its ability to recover realistic uncertainties, we split the data into a training (365,000 datapoints) and three testing datasets. The testing datasets are designed to test interpolation over small and large scales, and extrapolation. They are the following: 1) interpolation-testing covering all data over a 1.5 year period between July 1997 and December 1998 inclusive (25,000 datapoints); 2) extrapolation-testing covering all data in the last 1.5 years of the total dataset covering July 2009 to December 2010 (30,000 datapoints); and 3) randomtesting which is a randomised sample of $5 \%$ of the data not included in the other testing datasets $(20,000 \mathrm{k}$ datapoints). The Bayesian neural network is trained only on the training dataset and the three testing sets are held out for validating predictive ability and uncertainty quantification. 


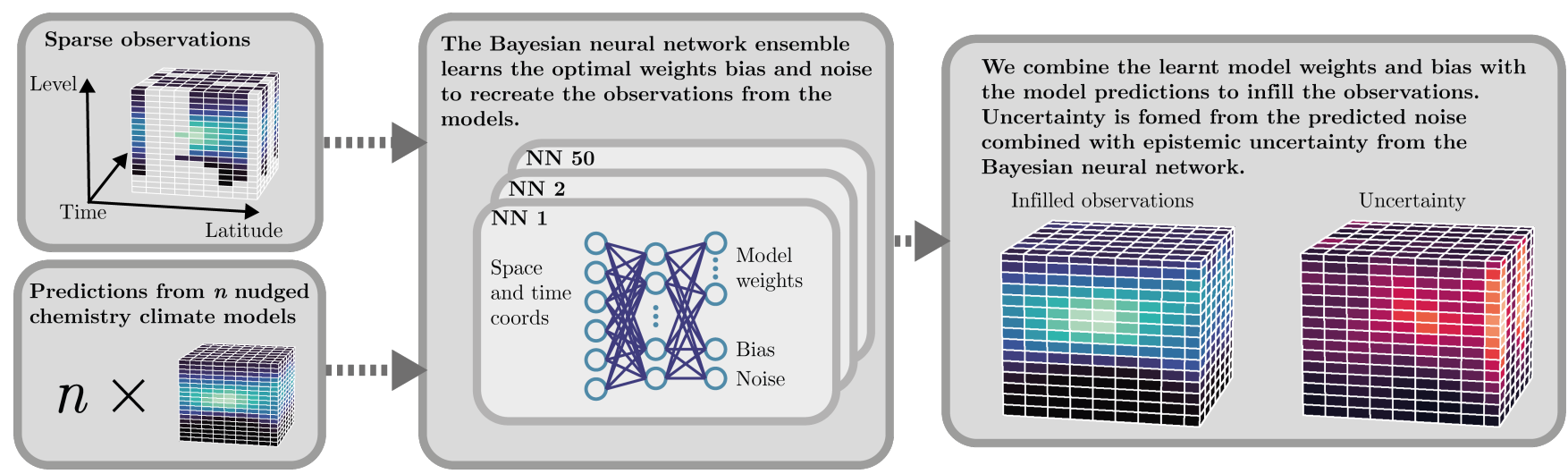

Figure 1. Depiction of the Bayesian neural network. It shows the overall framework of combining gridded observations with CCMs using the BNN to produce infilled predictions alongside uncertainties. The middle box also contains a simplified diagram of the neural network architecture.

\section{Methods}

\subsection{Bayesian neural networks for fusing CCMs and observations}

The Bayesian neural network we used to fuse CCMs and observations together is an extension of our earlier work (Sengupta et al., 2020), and is summarised in Figure 1. We took a similar approach to the task of infilling the sparsely sampled ozone observations $(o b s)$ by assuming that they can be modelled as a linear combination of $n$ nudged CCM outputs $\left(M_{i}\right)$, adjusted by weights $\left(\alpha_{i}\right)$, a bias $(\beta)$ and heteroscedastic noise $(\sigma)$ :

$o b s(\mathbf{x}, t)=\sum_{i=1}^{n}\left(\alpha_{i}(\mathbf{x}, t) M_{i}(\mathbf{x}, t)\right)+\beta(\mathbf{x}, t)+\sigma(\mathbf{x}, t)$.

These weights, bias and noise are modelled as spatially $(\mathbf{x})$ and temporally $(t)$ varying, allowing for both the fact that CCMs may better simulate certain spatial regions or certain seasons and that observational noise is not constant. We used the Bayesian neural network (BNN) to learn the optimal weights, bias and noise.

In general, BNNs are neural networks (NNs) over whose parameters a prior is specified and whose posterior distribution can be recovered by a variety of inference techniques (Neal, 2012). In this paper, we used an anchored ensemble of individual NNs to approximate Bayesian inference (Pearce et al., 2020). The BNN learns weights, bias and noise from the spatiotemporal inputs such that, when combined with model predictions, it can successfully replicate the observations over a training period within a specified level of uncertainty. Model weighting is a regression task for which there are numerous capable machine learning models. We justify the choice of a NN approach for reasons of scalability, since gridded model data, even at coarse resolutions, quickly becomes large. A detailed description of the statistical underpinnings of the BNN is presented by Sengupta 
et al. (2020), including the relevant derivations and a complete discussion of the BNN design. Here we summarise the main concepts of the BNN for combining observations and geophysical models.

The probabilistic nature of the BNN allows us to encode our prior knowledge within it and quantify uncertainty. Our prior for the model weights $(\alpha)$ is that for an individual $\mathrm{NN}$, at any point in time and space, any combination of models should be equally likely. Averaged over all NNs, this prior belief means the untrained prediction becomes the multi model mean, which is an appropriate starting point for model ensembles (e.g., Reichler and Kim, 2008; Knutti et al., 2010). Other priors are that the bias $(\beta)$ should be small and zero-centred, because the models should predominantly contribute to the prediction, and that the noise $(\sigma)$ should similarly be small and positive as the noise should not be so large that it inhibits finding optimal weights and bias. Overall, these priors mean that the output from an untrained BNN will be the multi model mean with a small bias, small noise and a large epistemic uncertainty which spans the range of predictions made by the different CCMs in the ensemble.

To encode our prior knowledge within a NN we have to determine what values the parameters of the NN can take in order to produce our prior distribution. NNs comprise of layers of neurons which have numerical weights and biases and it is these we encode the prior within. There are many combinations of values that the NN layer weights and biases can take to achieve this, meaning that our prior is actually a distribution over neural network parameters.

We encode the prior into the BNN by anchoring the trainable parameters (the NN weights and biases) of each NN ensemble member to a random draw from this prior distribution. This anchoring is a form of regularisation that ensures diversity in the NN predictions in accordance with our prior, from which we can quantify an uncertainty in the learnt weights and bias. Increased disagreement across the BNN in regions with no observations, due to the anchoring, means that we are suitably uncertain about the values of the weight of a CCM, the bias or the noise during extrapolation. This of course is a highly desirable characteristic. After training, individual NNs are sampled from an approximate posterior distribution and therefore, given an adequate number of anchored NNs, we can reconstruct an estimate of the posterior distribution. The BNN prediction is computed by taking the mean of the individual $\mathrm{NN}$ predictions and the epistemic uncertainty of the prediction is calculated as the standard deviation across the individual NN predictions. The epistemic uncertainty represents the uncertainty of the BNN. The total predictive uncertainty $\sigma_{\mathrm{TO}}$, combining noise predictions with epistemic uncertainty, is calculated as follows:

$\sigma_{\mathrm{TOT}}=\sqrt{\frac{1}{n_{e}} \sum_{j=1}^{n_{e}} \sigma_{j}^{2}+\frac{1}{n_{e}} \sum_{j=1}^{n_{e}} y_{j}^{2}-\left(\frac{1}{n_{e}} \sum_{j=1}^{n_{e}} y_{j}\right)^{2}}$,

where $n_{e}$ is the number of NN ensemble members, $\sigma_{j}$ is the predicted noise for each NN ensemble member, and $y_{j}$ is the prediction for each $\mathrm{NN}$ ensemble member.

\subsection{BNN training}

The BNN trained for the purpose of infilling the vertically resolved ozone consists of an ensemble of 48 NNs, an ensemble large enough to ensure the posterior distribution was suitably resolved. The $48 \mathrm{NNs}$ were independently initialised and anchored according to our priors before conducting prior predictive checks to ensure the untrained BNN output reflected our priors (the 
prediction of the multi model mean with small noise and small bias). The BNN was trained on the training dataset for 100,000 epochs on a cluster of 4 T4 GPUs, taking 10 hours to complete and costing about $£ 30$ in cloud computing credits (as of April 2021). The full training details are provided in the Supplementary Materials (Appendix A).

\section{The BNN ozone dataset (BNNOz)}

The trained BNN optimally fuses the 13 CCM predictions with the sparse BSTier0 observations with full consideration of uncertainty, producing a continuous vertically resolved ozone and uncertainty prediction, spanning $\{500-0.3 \mathrm{hPa}\}$ for the years 1980-2010. A subset of these infilled results is shown in Figure 2, highlighting the smoothness of the prediction and the variable nature of the predictive uncertainty.

\subsection{Testing and validation}

We assess the performance of the BNN ozone prediction (hereafter BNNOz) using the root mean squared error (RMSE) between BNNOz and the BSTier0 observations that were not part of the training dataset, as well as the fractional error, which calculates the absolute error relative to the true observational value. Fractional error is used in addition to the RMSE because the latter is dominated by regions of high ozone levels and is therefore not an informative measure of performance for regions of low levels. Alongside RMSE and fractional error, we measure how well the BNN quantifies uncertainty by calculating what portion of the BNNOz data falls within 1,2 and 3 standard deviations of the prediction, where the standard deviation is the uncertainty prediction from the BNN. Under a Gaussian assumption, we would expect these values to be $68.3 \%, 95.5 \%$ and $99.7 \%$ respectively.

Table 1. Analysis of the performance of the BNN predictions and uncertainty quantification for the training and testing data splits. Root mean squared error and fractional error are used to assess predictive skill, and the skill of the uncertainty prediction is calculated by the portion of data that fall within the uncertainty prediction. Under a Gaussian assumption these values would be $68.3 \%, 95.5 \%$ and $99.7 \%$ respectively.

\begin{tabular}{l|ccc} 
Data split & $\begin{array}{c}\text { Root mean } \\
\text { squared } \\
\text { error (ppm) }\end{array}$ & $\begin{array}{c}\text { Mean } \\
\text { fractional } \\
\text { error }(\%)\end{array}$ & $\begin{array}{c}\text { Percentage of points } \\
\text { within } 1,2,3 \\
\text { standard deviations (\%) }\end{array}$ \\
\hline Training & 0.14 & 1.2 & $80.0,97.8,99.6$ \\
Random testing & 0.15 & 1.5 & $79.1,97.4,99.5$ \\
Interpolation testing & 0.17 & 1.7 & $70.1,94.7,99.0$ \\
Extrapolation testing & 0.11 & 1.5 & $77.6,97.4,99.5$
\end{tabular}

The BNNOz prediction has been tested and validated against the three testing datasets to ensure that the BNN method can interpolate and extrapolate over large spatial regions and time periods of missing data, similar to those present in the original BSTier0 data. The results of these performance and uncertainty tests are shown in Table 1. The mean fractional error is between $1 \%$ and $2 \%$ for the different testing splits, showing that the infilling performance of the BNN is good and consistent across 


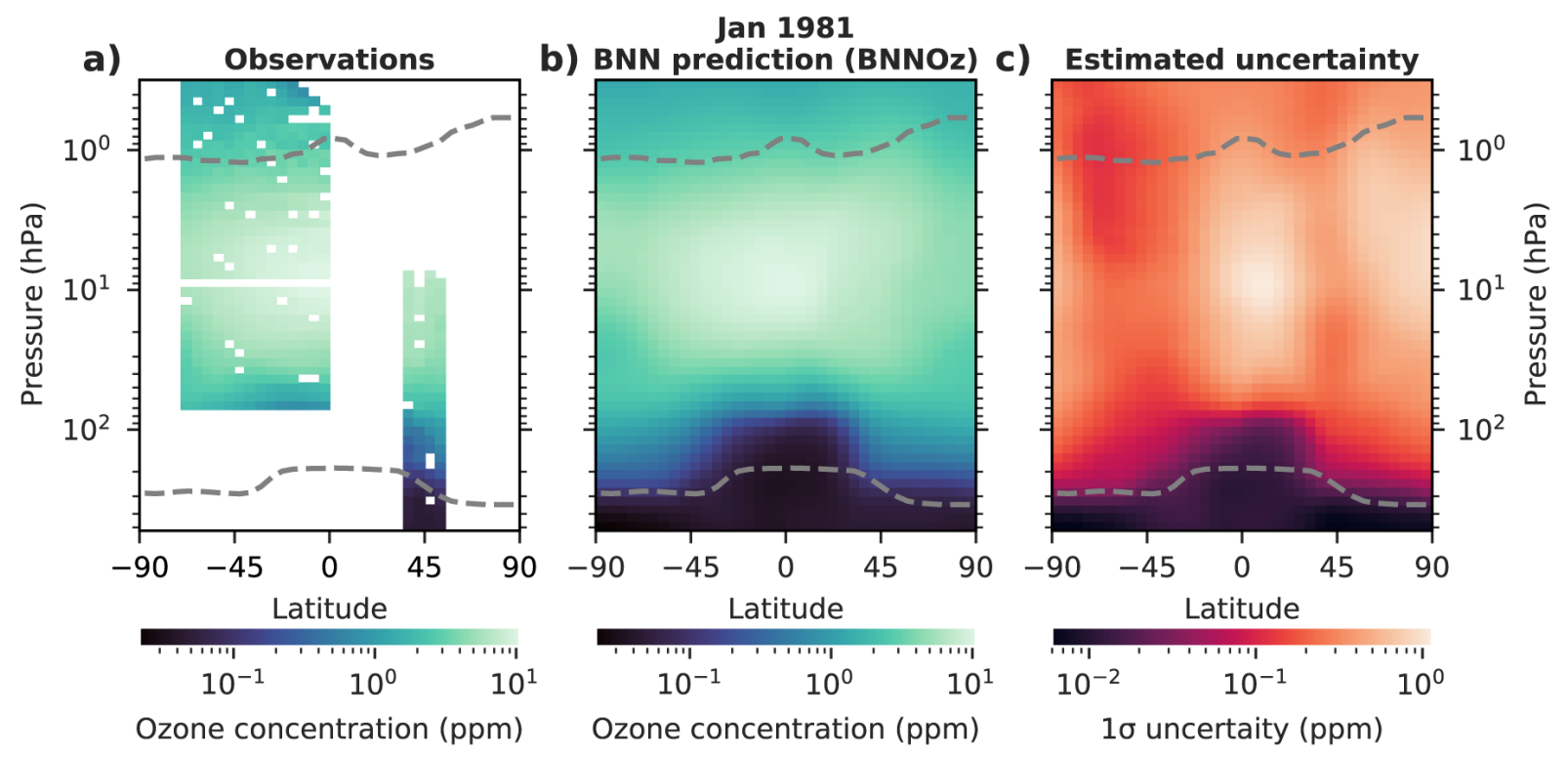

d)

Timeseries at $\mathbf{1 2 . 5}$ degrees latitude and $\mathbf{5 0 . 4} \mathrm{hPa}$

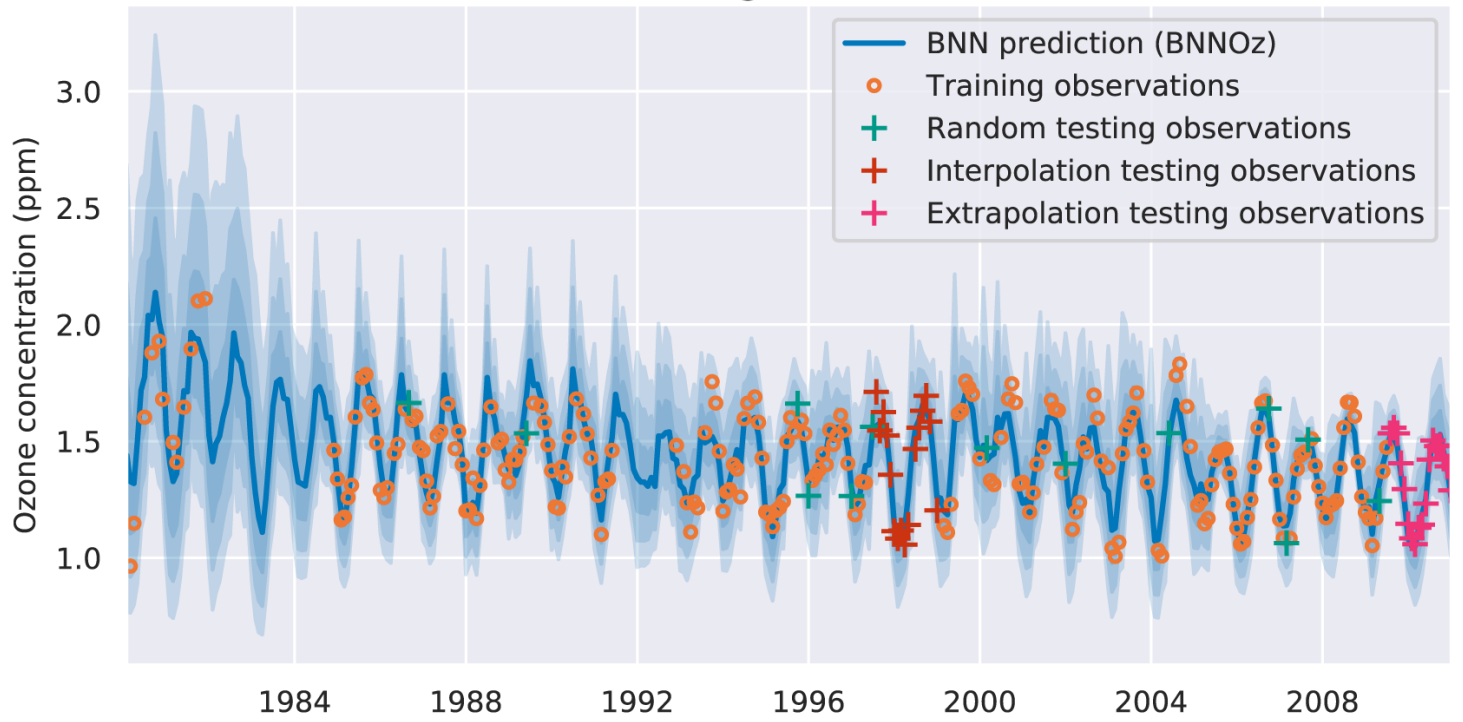

Figure 2. A snapshot of the ozone concentration predictions from the Bayesian neural network (BNN). The top row shows zonal mean plots for January 1981 of (a) the BSTier0 ozone observations used to train the BNN (Bodeker et al., 2013), (b) the infilled ozone prediction from the BNN and (c) the estimated uncertainty in that prediction. Dashed grey lines in (a) to (c) show the approximate positions of the tropopause (lower) and stratopause (upper), defined using NCEP reanalysis (Kalnay et al., 1996) and CCMI model averages respectively. Panel (d) shows an example predicted monthly mean ozone timeseries from the BNN at $12.5^{\circ} \mathrm{N}$ and $50.4 \mathrm{hPa}$. The markers show the separate sets of observations used for training and testing, as specified in the legend (see section 2.3 for details), and the shading indicates the $68 \%$, $95 \%$ and $99.7 \%$ confidence intervals (moving darker blue to light blue) for the BNN prediction. 


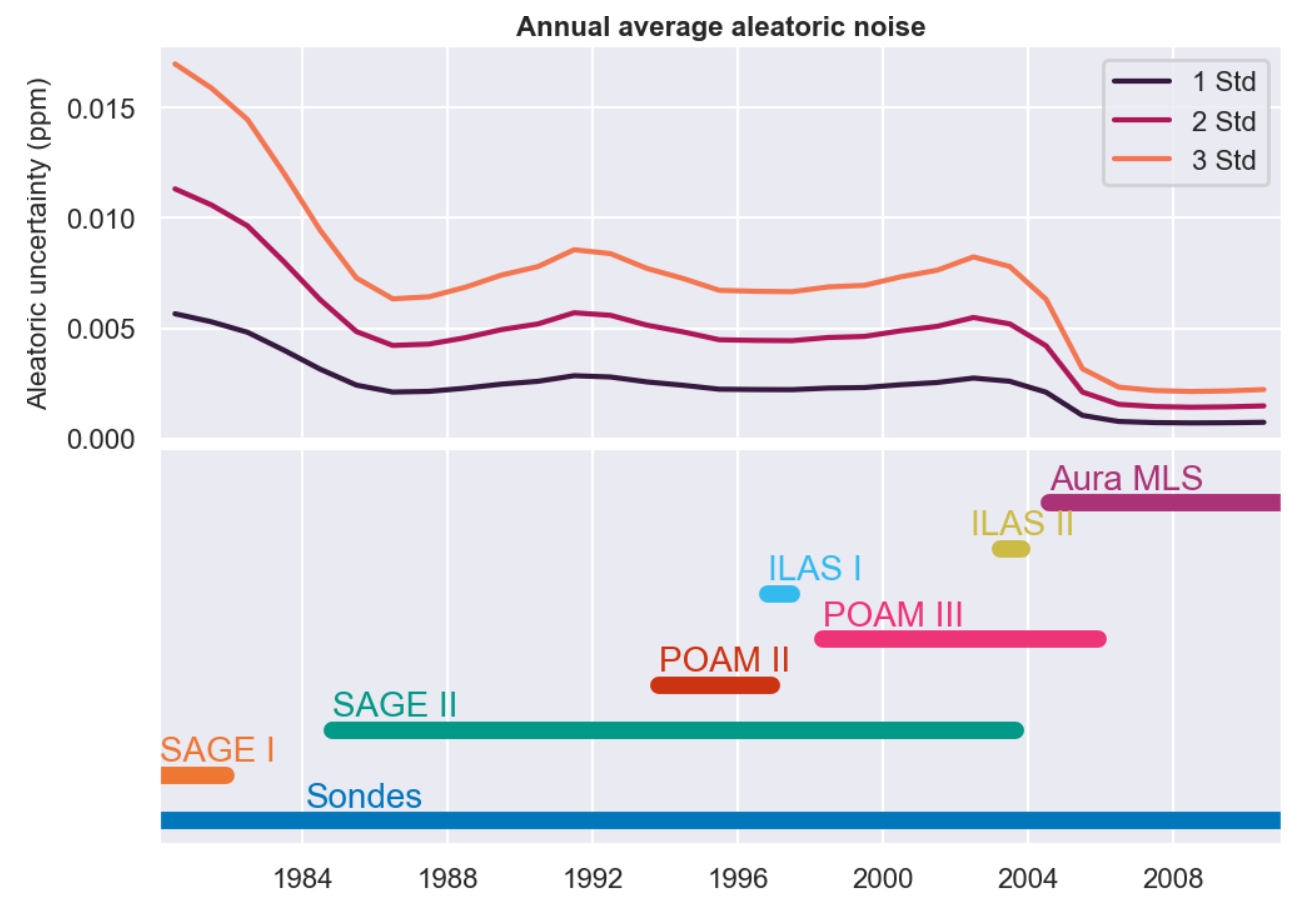

Figure 3. The average annual aleatoric uncertainty (standard deviation) calculated by the BNN (top panel), shown relative to the temporal coverage of satellites used in the BSTier0 dataset (bottom panel). The aleatoric noise is a measure of the estimated uncertainty in the observations.

both interpolation and extrapolation tasks. Low fractional error and low RMSE scores across the training and testing datasets demonstrate that the BNN is capable of reconstructing the observations accurately from the ensemble of CCMs. Furthermore, this predictive skill suggests that the BNN can successfully learn meaningful model weights, bias and noise.

The uncertainty quantification scores, displayed in the final column of Table 1, show that the BNNOz uncertainty estimates are good and are even slightly under-confident for all the testing datasets. Uncertainty estimates of the BNNOz are comprised of both aleatoric (observational) and epistemic (knowledge) uncertainties, and vary in time and space to capture that different instruments with different levels of precision are used in the BSTier0 observational dataset. Figure 3 shows how the estimated annual aleatoric uncertainty is dependent on which satellite products are used. Uncertainty is high early in the record and decreases to a minimum after 2004 when the high quality AuraMLS (Waters et al., 2006) satellite data becomes the main satellite product used. Although the BNN is not given explicit information about the construction of the original dataset, by allowing BNN parameters to vary temporally and spatially the BNN has captured and accounted for complex features of the underlying data.

We would typically expect the performance of the BNN to be lower for extrapolation than interpolation, as extrapolation tasks are constrained by less surrounding data than interpolation tasks. However, for this set of models and observations the BNN extrapolates more skillfully. The reason for this can be traced back to the construction of the testing datasets and the 
original BSTier0 dataset we are infilling, which is a conglomerate of measurements from multiple instruments. Firstly, the observational noise decreases in time, as shown in Figure 3, meaning that the latter years covering the extrapolation test (Jul2009-Dec2010) are likely of higher quality than the data used in the interpolation test (Jul1997-Dec1998). Secondly, the observational data coverage increases throughout the record meaning the extrapolation testing period is better constrained. These performance results do not mean that the $\mathrm{BNN}$ is better at extrapolating than interpolating; the opposite is true in general and it is due to varying quality and availability of ozone observations.

\subsection{Comparison to existing vertically resolved ozone datasets}

240 We now compare BNNOz to four existing datasets of vertically resolved ozone datasets, to highlight some shared similarities and differences, and to demonstrate how the extrapolation capabilities of the BNN allow new exploration of under observed regions. Table 2 summarises the details of the comparator datasets, and Figure 4 indicates their vertical coverage. Their latitudinal coverage varies from global $\left(90^{\circ} \mathrm{S}-90^{\circ} \mathrm{N}\right)$ to near global $\left(60^{\circ} \mathrm{S}-60^{\circ} \mathrm{N}\right)$, depending on the observations and infilling methods used. The BASIC and SBUV cohesive datasets (acronyms are introduced in Table 2) do not extend down into the troposphere whereas SWOOSH and BSTier1.4 do. None of these datasets represent independent comparisons to the BNN prediction as they are all constructed, at least partially, from the same satellite and observational products present in the BSTier0 data used to train the BNN.

Table 2. Descriptions of the comparative datasets used. BNNOz, BSTier1.4, and SWOOSH are all infilled datasets, whereas BASIC and SBUV are unfilled. We used the version of SWOOSH that was filled by a combination of replacing latitudinal gaps with their corresponding equivalent latitude measurement and radial basis function interpolation to fill smaller gaps, as this is the most complete SWOOSH ozone dataset. BSTier1.4 is filled using a multi-linear regression of global time series expanded into harmonic components. The BASIC (BAyeSian Integrated and Consolidated composite ozone time-series dataset) version we used for comparison did not use SBUV(/2) observations.

\begin{tabular}{|c|c|c|c|c|}
\hline Dataset & Acronym & $\begin{array}{l}\text { Temporal } \\
\text { coverage }\end{array}$ & $\begin{array}{l}\text { Vertical } \\
\text { coverage }\end{array}$ & Reference(s) \\
\hline BNN prediction & $\mathrm{BNNOz}$ & 1980-2010 & $500-0.3 \mathrm{hPa}$ & \\
\hline $\begin{array}{l}\text { Bodeker Scientific } \\
\text { Tier1.4 }\end{array}$ & BSTier1.4 & 1979-2016 & $\begin{array}{c}878.4- \\
0.046 \mathrm{hPa}\end{array}$ & Bodeker et al. (2013) \\
\hline $\begin{array}{l}\text { SWOOSH (eq lat } \\
\text { and anomaly filled) }\end{array}$ & SWOOSH & $1984-$ & $316.2-1 \mathrm{hPa}$ & Davis et al. (2016) \\
\hline $\begin{array}{l}\text { BASIC (without } \\
\text { SBUV obs) }\end{array}$ & BASIC & $1985-2018$ & $\begin{array}{l}146.8- \\
1.2 \mathrm{hPa}\end{array}$ & $\begin{array}{c}\text { Alsing and Ball (2017) } \\
\text { Ball et al. (2017) }\end{array}$ \\
\hline SBUV cohesive & SBUV & $1980-$ & $50-0.5 \mathrm{hPa}$ & Miller et al. (2002) \\
\hline
\end{tabular}



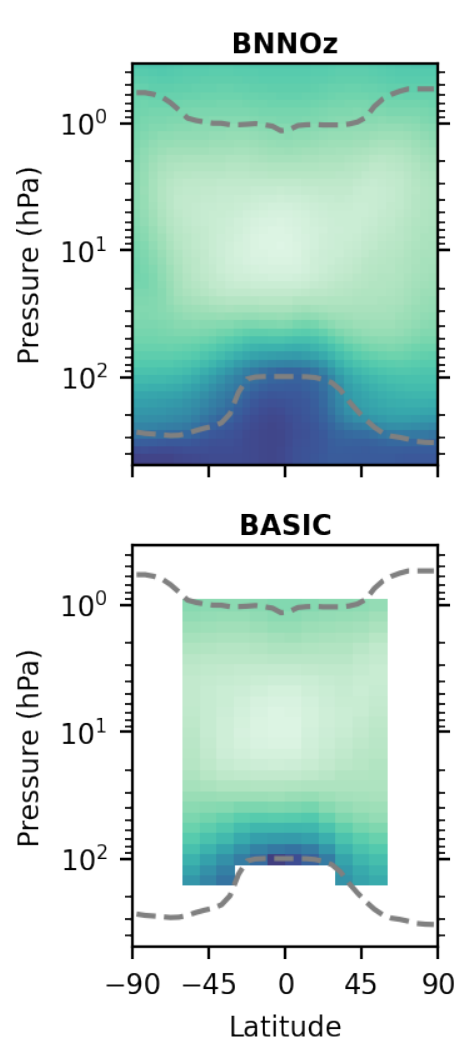

BSTier1.4

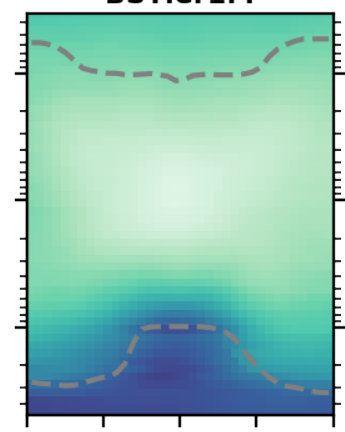

SBUV

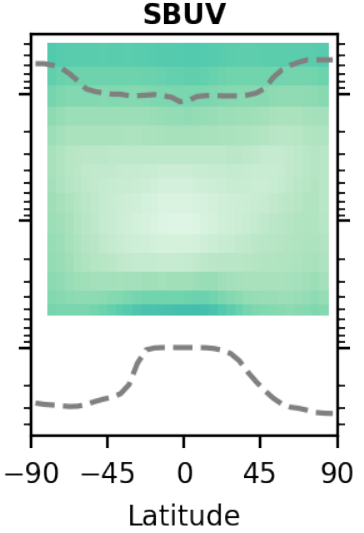

swoosh
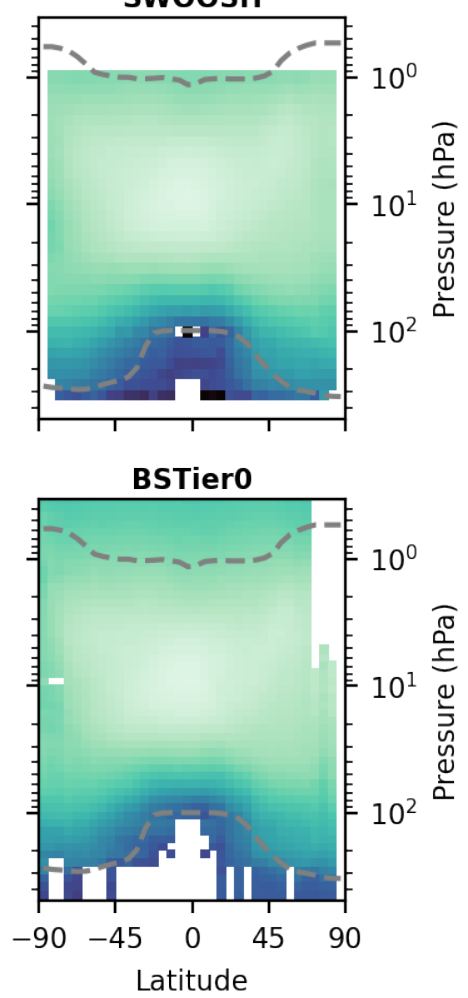

Figure 4. Monthly averaged ozone concentration for March 1995 for 6 datasets showing typical latitudinal and vertical coverage. Dashed grey lines show the approximate positions of the tropopause and stratopause. Apparent missing data in the tropical tropopause for SWOOSH are caused by the incompatibility of negative ozone concentrations with log scaling.

\subsubsection{Ozone anomalies}

To compare ozone datasets, demonstrate the improved coverage of BNNOz and highlight uncertainty, Figures 5 and 6 show ozone anomalies for set latitudinal regions and pressure levels, based on the analyses presented in the Global Ozone chapter (Braesicke et al., 2018) of the World Meteorological Organisation (WMO) Scientific Assessment of Ozone Depletion report (WMO, 2018). Anomalies are calculated as the annual mean ozone anomaly from deseasonalised time series, relative to the base period of 1998-2008, at pressure levels of 2, 10, 20 and $70 \mathrm{hPa}$.

Figure 5 shows ozone anomalies at pressure levels of $2,10,20,70 \mathrm{hPa}$ for the near global average $\left(60^{\circ} \mathrm{S}-60^{\circ} \mathrm{N}\right)$ and averaged over the southern mid-latitudes $\left(60^{\circ} \mathrm{S}-35^{\circ} \mathrm{S}\right)$, tropics $\left(20^{\circ} \mathrm{S}-20^{\circ} \mathrm{N}\right)$ and northern mid-latitudes $\left(35^{\circ} \mathrm{N}-60^{\circ} \mathrm{N}\right)$, which are regions covered by all datasets. Figure 6 shows anomalies at the same pressure levels for the southern polar cap $\left(90^{\circ} \mathrm{S}-60^{\circ} \mathrm{S}\right)$, northern polar cap $\left(90^{\circ} \mathrm{S}-90^{\circ} \mathrm{N}\right)$ and the entire globe $\left(90^{\circ} \mathrm{S}-90^{\circ} \mathrm{N}\right)$, which are regions that require some form of infilling and as a result are only shown for BNNOz, BSTier1.4 and SWOOSH. For both figures, the annual mean ozone anomalies are calculated from a deseasonalised (relative to 1998-2008) ozone time series and are relative to a 1998-2008 base period. 

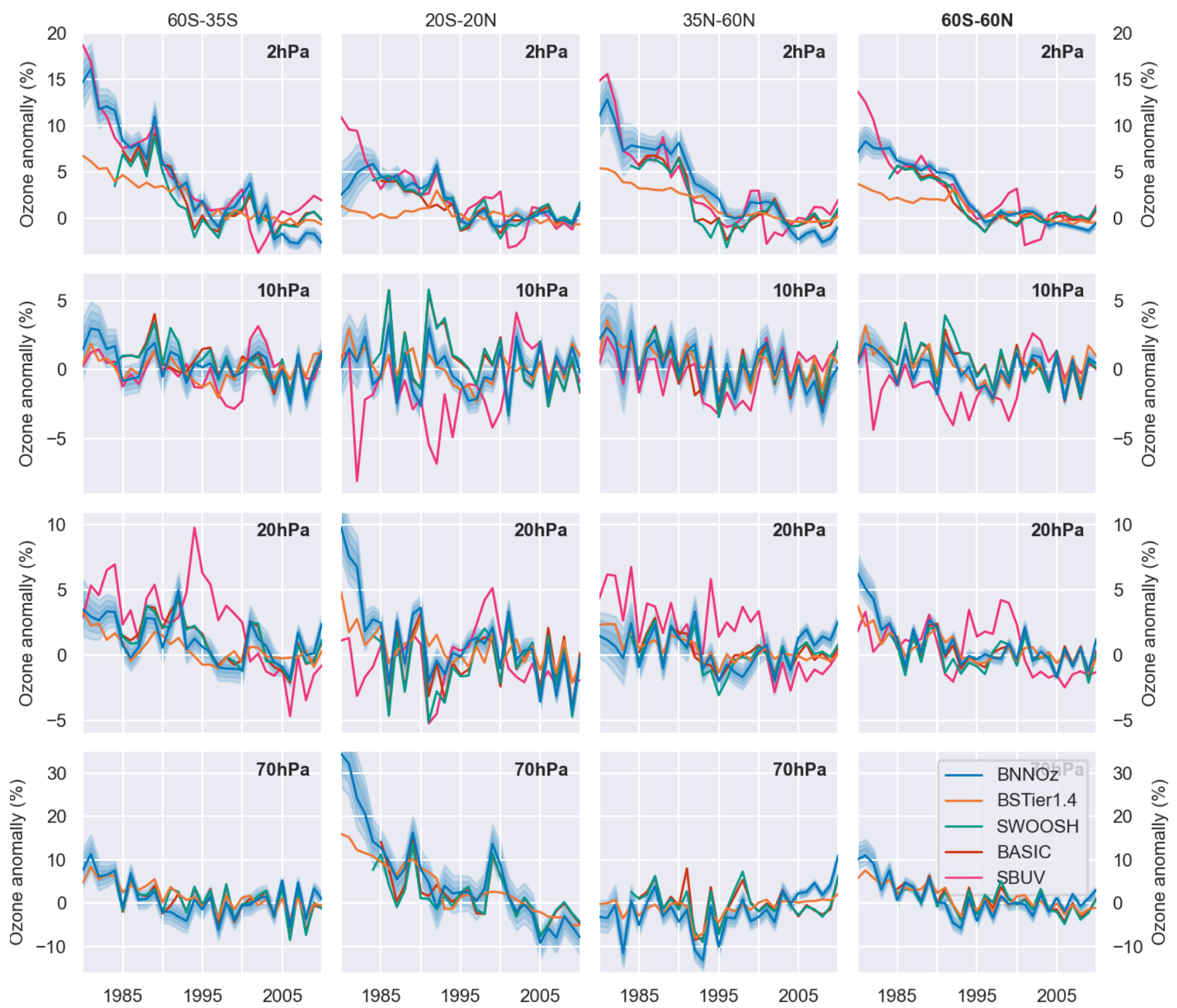

Figure 5. Comparison of annual mean deseasonalised ozone anomalies from a range of ozone datasets: BNNOz, BSTier1.4, SWOOSH, BASIC and SBUV (cohesive). Anomalies are shown for pressure levels $2,10,20$ and $70 \mathrm{hPa}$, averaged over $60^{\circ} \mathrm{S}-35^{\circ} \mathrm{S}$ (first column), $20 \mathrm{~S}-20 \mathrm{~N}$ (second column), $35^{\circ} \mathrm{N}-60^{\circ} \mathrm{N}$ (third column) and $60^{\circ} \mathrm{S}-60^{\circ} \mathrm{N}$ (last column). The anomalies are calculated relative to the base period 1998-2008 and are area weighted. The shading around the BNNOz shows uncertainty at $68 \%, 95 \%$ and $99.7 \%$ confidence intervals. This figure is based on figures 3-15 and 3-16 from the 2018 WMO Ozone Assessment Report (WMO, 2018) itself adapted from the SPARC/IO3C/GAW LOTUS (Long-term Ozone Trends and Uncertainties in the Stratosphere) report (Petropavlovskikh et al., 2018). 
90S-60S
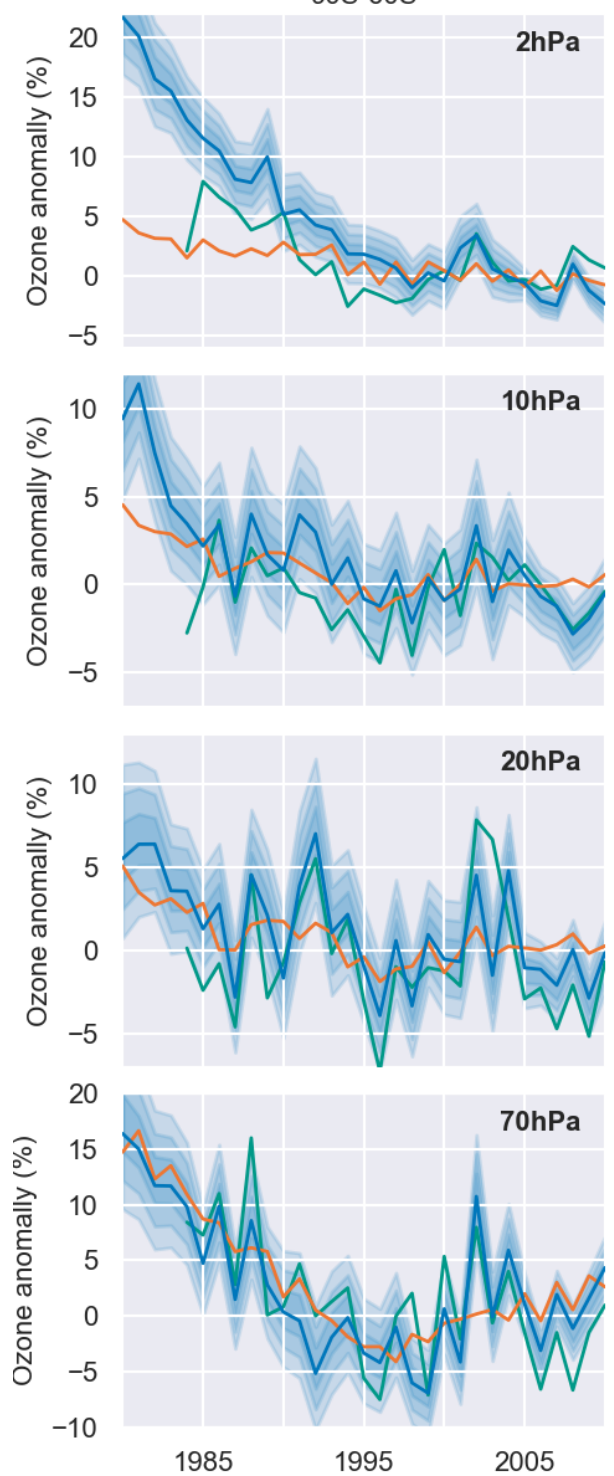

$60 N-90 N$

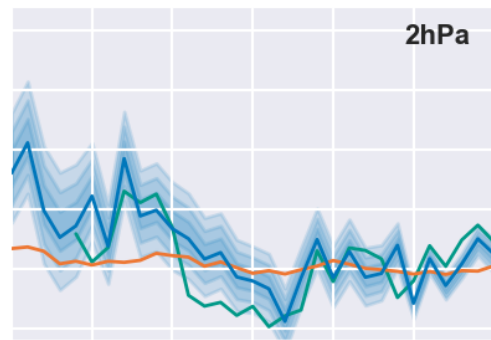

$10 \mathrm{hPa}$

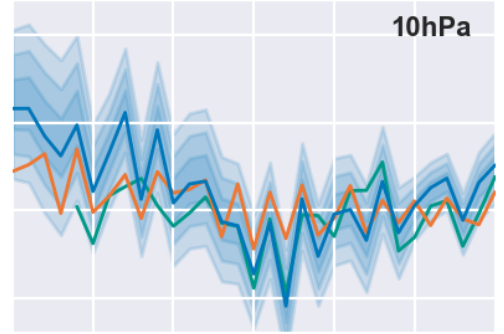

$20 \mathrm{hPa}$
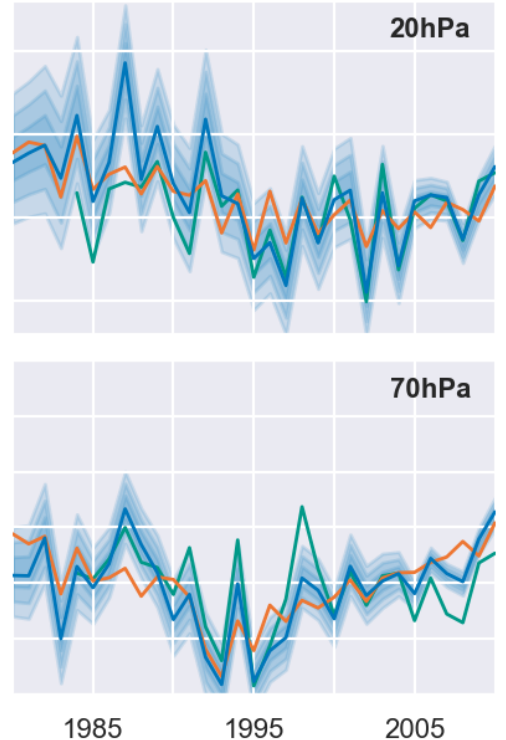

90S-90N

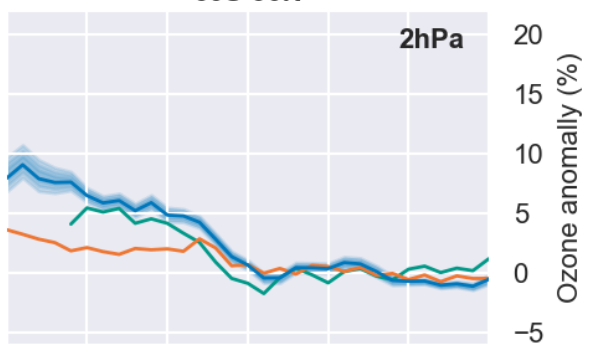

$10 \mathrm{hPa}$

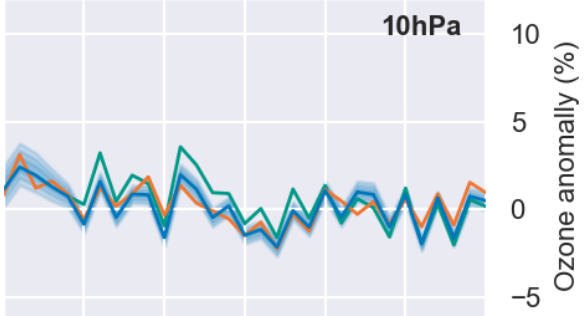

$20 \mathrm{hPa}$

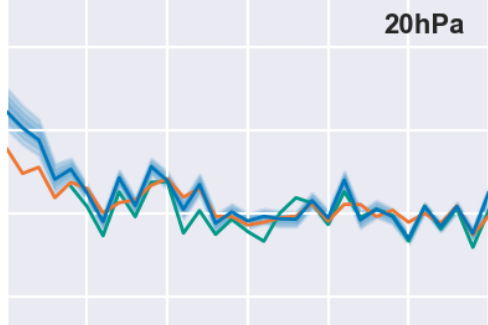

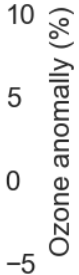

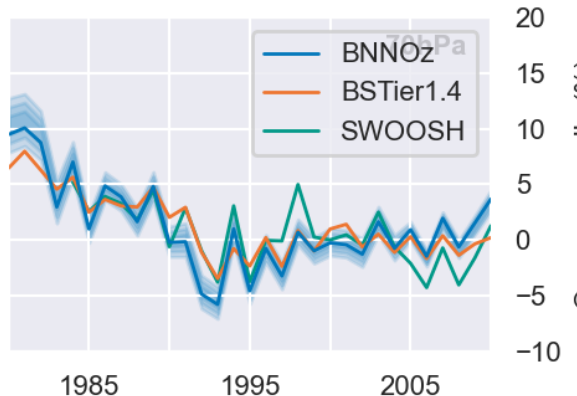

Figure 6. Comparison of annual mean deseasonalised ozone anomalies from infilled ozone datasets: BNNOz, BSTier1.4 and SWOOSH. As per Figure 4, but with anomalies averaged over $90^{\circ} \mathrm{S}-60^{\circ} \mathrm{S}$ (left column), $60^{\circ} \mathrm{N}-90^{\circ} \mathrm{N}$ (middle column), $90^{\circ} \mathrm{S}-90^{\circ} \mathrm{N}$ (right column). The anomalies are calculated relative to the base period 1998-2008 and are area weighted. The shading around the BNNOz shows uncertainty at $68 \%, 95 \%$ and $99.7 \%$ confidence intervals. The BASIC and SBUV datasets are not shown as they have incomplete coverage beyond the range $60^{\circ} \mathrm{S}$ to $60^{\circ} \mathrm{N}$. This figure is based on figures 3-15 and 3-16 from the 2018 WMO Ozone Assessment Report (WMO, 2018) itself adapted from the SPARC/IO3C/GAW LOTUS (Long-term Ozone Trends and Uncertainties in the Stratosphere) report (Petropavlovskikh et al., 2018). 
Figure 5 shows that BNNOz is in good agreement with other vertically resolved ozone products for the four regions within $60^{\circ} \mathrm{S}-60^{\circ} \mathrm{N}$. The similarity between the $\mathrm{BNNOz}$ and other products is greater at higher pressures (lower altitudes) where the BNNOz uncertainty largely encompasses other datasets, although it decreases with altitude. In time periods of higher data coverage the datasets are more likely to be in agreement, compared to early in the record where data availability is lower. This drop in data availability in the early part of the datasets is reflected in the increasing uncertainty of BNNOz, particularly between 1980-1985. Overall, for near-global, mid-latitude and tropical regions, the BNNOz successfully captures the longterm trends and smaller fluctuations, caused by forcing such as the solar cycle and the El Niño Southern Oscillation (ENSO) (WMO, 2018), that are seen across the datasets.

Figure 6 explores the predictions over polar regions and the global average, where the differences between ozone products should be more apparent due to the need for infilling in these regions. The effect of greater data sparsity over these regions, compared to the more data rich near global predictions in Figure 5, is seen in the increased BNNOz uncertainty. For the polar cap predictions $\left(90^{\circ} \mathrm{S}-60^{\circ} \mathrm{S}\right.$ and $\left.60^{\circ} \mathrm{N}-90^{\circ} \mathrm{N}\right)$ the SWOOSH infilled predictions are typically in agreement with $\mathrm{BNNOz}$ within the uncertainty. The infilled BSTier1.4 prediction similarly falls mostly with the BNNOz uncertainty but displays much less interannual variability than $\mathrm{BNNOz}$ and $\mathrm{SWOOSH}$, particularly at higher altitudes. As the underlying observations are then same between BNNOz and BSTier1.4, this difference is therefore a result of the BSTier1.4 infilling method which has led to a smoothing of the ozone anomaly time series. In addition to maintaining variability, BNNOz has the benefit of extending the other global infilled product SWOOSH to five years earlier.

\subsubsection{Ozone trends}

Ozone trends are typically calculated using a regression model which isolates the trend from background meteorological influences and known drivers of stratospheric ozone (Petropavlovskikh et al., 2018). Here, we calculate ozone trends using dynamical linear modelling (DLM) which performs regression against the same variables as the more commonly used multiple linear regression (MLR), but allows for a smoothly varying nonlinear ozone trend, unlike MLR. Using code from Alsing (2019), our implementation of DLM follows Ball et al. (2018) using the same regression time series: a latitudinally resolved stratospheric aerosol optical depth (Thomason et al., 2018), $30 \mathrm{~cm}$ radio flux (for solar variability) (de Wit et al., 2014), an ENSO index (NCAR, 2019), and an index of the quasi-biennial oscillation (QBO) using zonal winds at both 30 and $50 \mathrm{hPa}$ (Berlin, 2021). Vertically resolved ozone trends for each dataset are calculated 1985-1997 (pre-1997) and 1998-2010 (post1997) as 1997 was the approximate peak of halogen-containing ozone-depleting substances (Newman et al., 2007). The year 1997 also bisects the trend, enabling comparison with existing analysis performed with piecewise MLR (Petropavlovskikh et al., 2018). We then calculate percentage ozone change relative to the trend value at 1997.

Vertically resolved ozone trends for BNNOz and comparative datasets are shown in Figures 7 and 8 for the same latitudinal bands used in Figures 5 and 6. For the pre- 1997 trends in the regions between $60^{\circ} \mathrm{S}-60^{\circ} \mathrm{N}$ (Figures $7 \mathrm{a}, \mathrm{b}, \mathrm{c}$ and d), strong agreement is seen between BNNOz and the other datasets, particularly in the upper stratosphere where all datasets show significant (at 3-sigma) ozone depletion. For post-1997 trends (Figures 7 e, f, g and h), BNNOz similarly falls mainly within the dataset spread and shows neither significant widespread depletion or recovery. 

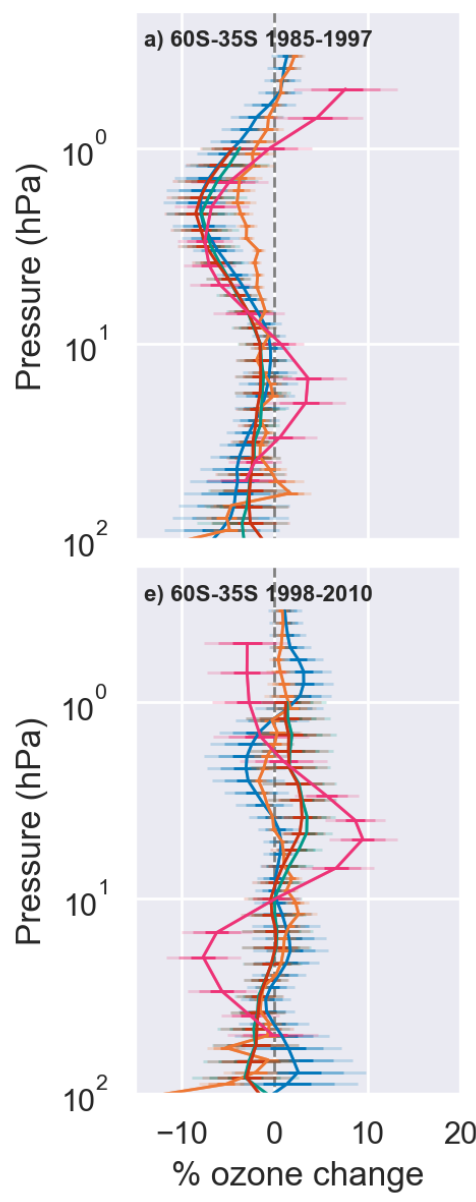
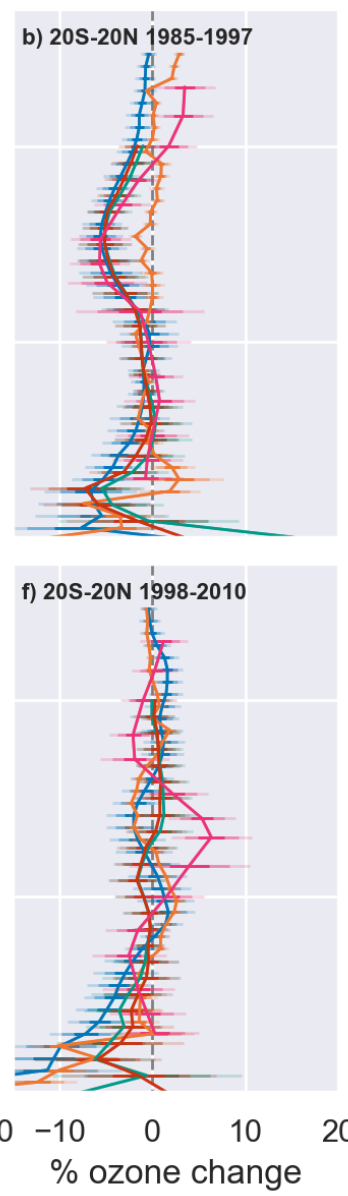

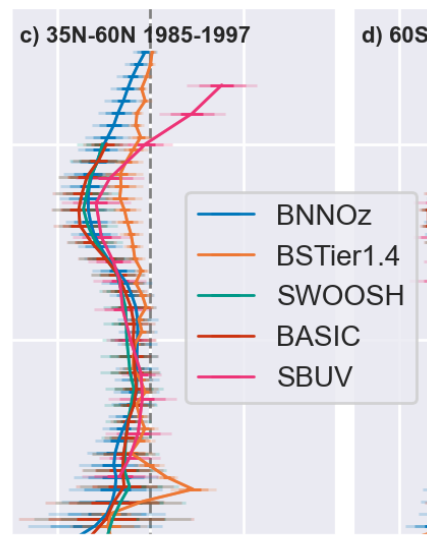

g) $35 \mathrm{~N}-60 \mathrm{~N} 1998-2010$

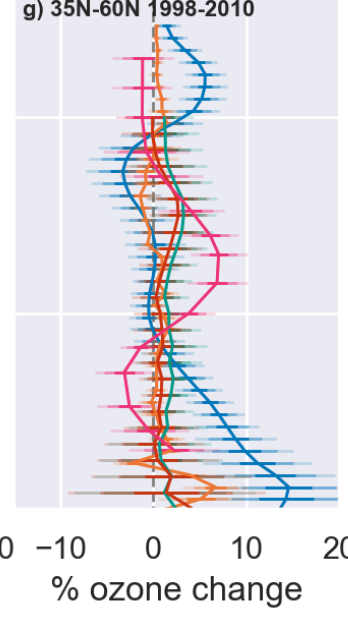

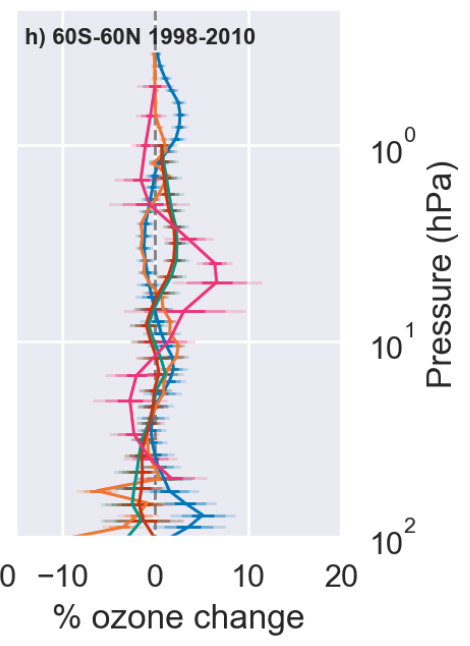

问
$10^{2}$

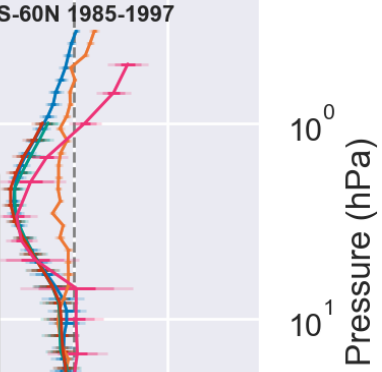

Figure 7. Ozone trends calculated using dynamical linear modelling (DLM) as a percentage ozone change relative to 1997, for 5 ozone datasets exclusive of polar regions. Trends are shown for pre-1997 (top row) over latitude bands $60^{\circ} \mathrm{S}-35 \mathrm{~S}, 20^{\circ} \mathrm{S}-20^{\circ} \mathrm{N}, 35^{\circ} \mathrm{N}-$ $60^{\circ} \mathrm{N}$ and $60^{\circ} \mathrm{S}-60^{\circ} \mathrm{N}$ (a, b, c and d respectively), and for post-1997 (bottom panel) for the same latitude bands (e, f, g and h). The coloured lines represent each dataset and are shown with shaded uncertainty bars (1,2 and 3 standard deviations) calculated from the DLM trend estimation. 
For the pre-1997 trends over, and including, the polar regions (Figures $8 \mathrm{a}, \mathrm{b}$ and c), SWOOSH and BNNOz are in reasonable agreement with one another especially for globally averaged ozone (Figure $8 \mathrm{c}$ ). Similarly to near global regions, the BSTier1.4 displays a much weaker but more confident trend. BNNOz estimates a peak ozone reduction of $10 \%$ at $1 \mathrm{hPa}$ over the southern polar cap for the period 1985-1997, equating to a loss of $0.26 \mathrm{ppm} \mathrm{dec}^{-1}$. At this same location SWOOSH and BSTier1.4 estimate significantly lower losses of $0.094 \mathrm{ppm} \mathrm{dec}^{-1}$ and $0.052 \mathrm{ppm} \mathrm{dec}^{-1}$ respectively. Disparity in the trend estimates is largely caused by two factors. Firstly, datasets consist of various observational sources compiled and assimilated differently which results in significantly different datasets and therefore trends. Secondly the infilling methods will have an impact on the ozone datasets, which will be particularly exacerbated over polar regions. For example, BSTier1.4 extrapolates using an expanded form of MLR and presents different ozone anomalies and trends compared to BNNOz, itself based on the same observational data (BSTier0). This difference between BSTier1.4 and BNNOz is even more apparent in Figures $8 \mathrm{~d}$, e and f, that show post-1997 trends, where the three continuous datasets (BNNOz, BSTier1.4 and SWOOSH) are in disagreement about recovery over the southern pole and globally.

That the calculated trends disagree, whilst having a high confidence of the disagreement, is strongly indicative that the differences are caused by the underlying observations. For that reason, it is difficult to determine whether datasets differ due to their infilling method or their observational foundation.

\section{Conclusion}

We have described the BNN methodology of model-observation fusion and demonstrate an application of producing a globally continuous dataset of vertically resolved ozone (BNNOz), extending our original application of the BNN in producing a total ozone column dataset (Sengupta et al., 2020). Using the BNN, we can combine physically and chemically realistic chemistryclimate model output with observations to generate predictions of ozone that are accurate and have an associated uncertainty. This Bayesian deep learning method successfully extrapolates over systematically under-observed regions and periods, as it relies on chemistry-climate models rather than a regression model-based method for the extrapolation. We have demonstrated the extrapolation and interpolation ability of the BNN and compared the BNNOz to widely used datasets. We anticipate a more exhaustive comparison and validation of BNNOz against other existing datasets when output from the next generation of CCM simulations, including CCMI phase 2, are available. Using newer models which simulate closer to the present day than CCMI-1 models, will have the additional benefit of extending the temporal converge of future versions of the BNNOz.

Alongside our original paper (Sengupta et al., 2020), the BNN has been applied to infilling historic surface ozone by blending CCMs with surface station data (Sun and Archibald, 2021). However, we note this latter application uses free running CCMs rather than specified dynamics CCMs. The BNN was not designed to handle these applications because a direct comparison between observations and models is needed at every point in space and time. Such comparisons are fair for specified dynamics models, where the models are nudged to simulate realistic meteorology and therefore have the chance to capture the influence of weather variability on a given observation. However, comparisons are not fair for free running models, where the meteorology is unconstrained by SSTs or the atmospheric state and will vary between the different models and from what was observed. 

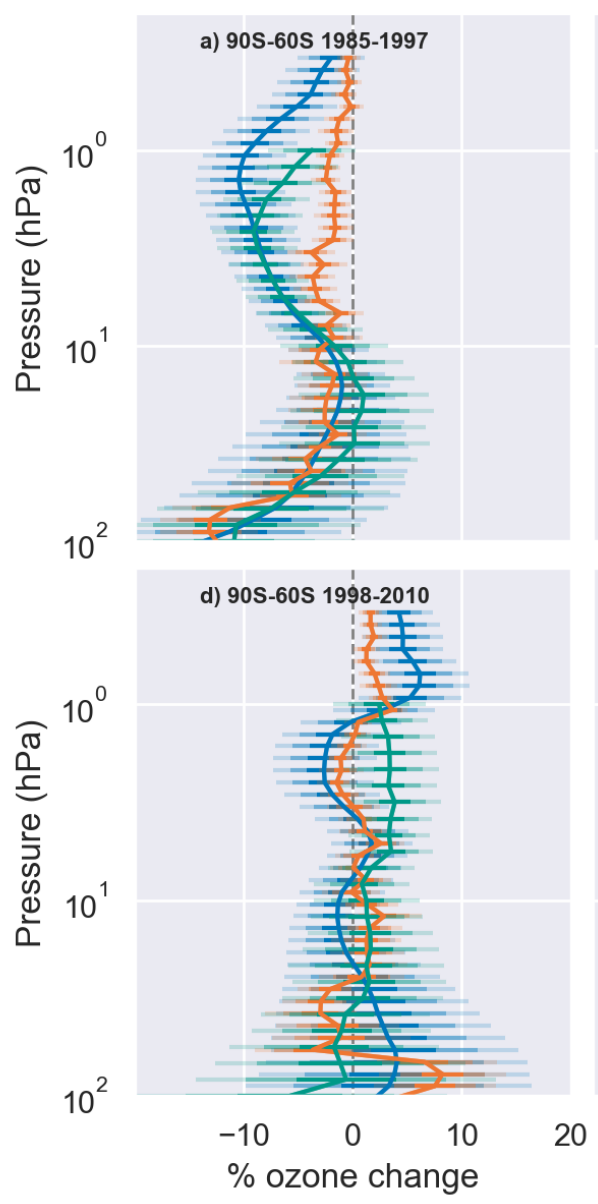
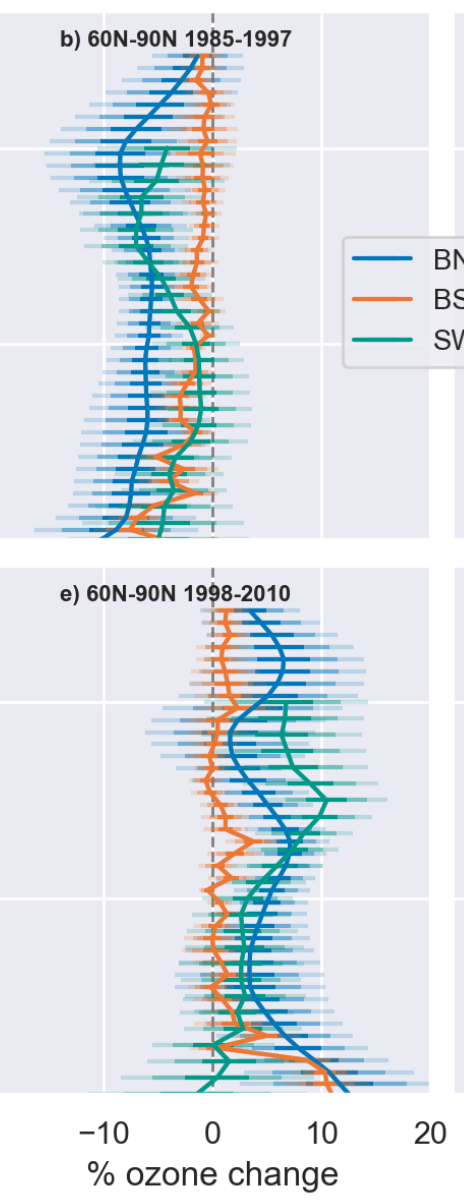

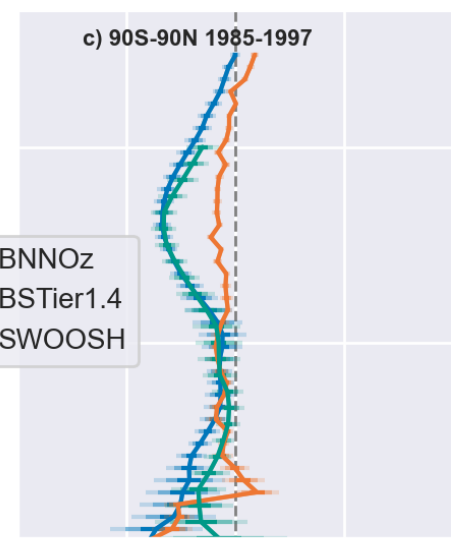

$10^{2}$

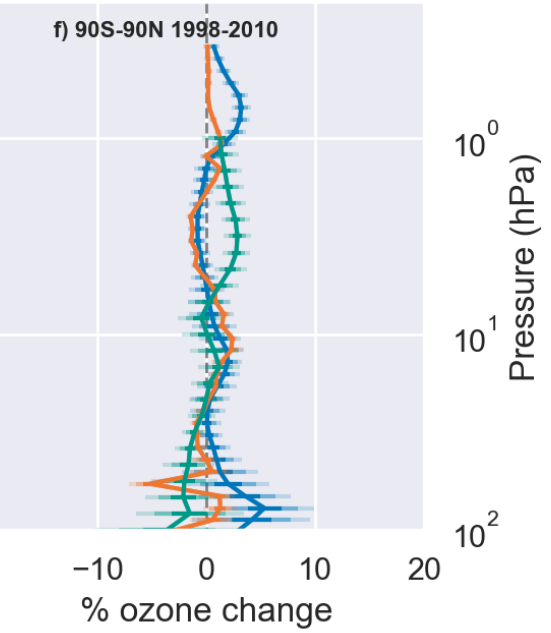

Figure 8. Ozone trends calculated using dynamical linear modelling (DLM) as a percentage ozone change relative to 1997, for 5 ozone datasets inclusive of polar regions. Trends are shown for pre- 1997 (top row) over latitude bands $90^{\circ} \mathrm{S}-60^{\circ} \mathrm{S}, 60^{\circ} \mathrm{N}-90^{\circ} \mathrm{N}$, and $90^{\circ} \mathrm{S}-90^{\circ} \mathrm{N}$ (a, b and c respectively), and for post-1997 (bottom panel) for the same latitude bands ( $\mathrm{d}, \mathrm{e}$, and f). The coloured lines represent datasets that have consistent near global coverage and are shown with shaded uncertainty bars (1, 2 and 3 standard deviations) calculated from the DLM trend estimation. 
This means that point-wise comparisons across simulations and observations are not as meaningful. A future extension of our BNN framework will be to include free running model simulations and to appropriately validate the results.

Our BNN approach to infilling observations has a number of advantages over other commonly used methods. It is a Bayesian approach which, as highlighted by Ball et al. (2017), is robust to unknown observational uncertainty and quantifies both statistical and observational uncertainty. Given the construction of the prediction, from weighted models and bias, it is interpretable as model contributions can be scrutinised spatially and temporally, to encourage trust beyond other opaque ML methods. This interpretability also furthers our understanding of the underlying observations, accounting for the varied quality of different observational sources and assimilation methods. As the BNN predictions are based on an ensemble of physically realistic models, we maintain accurate interannual variability, unlike linear regression methods that can smooth infilled output (e.g., Bodeker et al., 2013), and can recover trends, unlike infilling techniques that interpolate to climatological averages (e.g., Davis et al., 2016). As such, the BNNOz dataset is less limited by the assumptions made by these other infilling approaches.

The infilled prediction is strongly influenced by the choice of the infilling method. This is especially seen by comparing BNNOz and BSTier1.4 that use different infilling methods but the same original dataset. For BSTier1.4 the ozone anomalies tend to be more smoothly varying than BNNOz, indicating a lower ability to capture interannual variability. The differences between the approaches are more pronounced for ozone trend analyses, where BSTier1.4 exhibits a smaller trend than BNNOz, particularly in regions such as the poles that require more infilling. Differences in ozone trends and anomalies originate in the infilling methods, demonstrating the importance of investigating and testing the various methods, and providing principled uncertainty quantification.

Separate to differences caused by infilling methods, comparison between datasets in regions with good observational coverage show us that differences in ozone trends and anomalies are also due to the underlying observations. This may originate from the observational products used, retrieval methods or bias correction and as a result, infilled predictions will be highly dependent on these choices (WMO, 2018). Even with a principled infilling technique such as the BNN, the infilled product can only be as good as the ground-truth observational data it learns from. Future efforts therefore, should concentrate on improvements in observational data assimilation and pre-processing, or end-to-end approaches from satellite retrieval to infilling which would allow the propagation of errors throughout all the processing.

Code and data availability. The ML training dataset and output BNNOz dataset are archived on zenodo (Amos et al., 2021). Up to date code for the BNN and the analysis in this manuscript is available on GitHub at https://github.com/mattramos/VertOzone-BNN/ and is also archived (Amos, 2021). 
The reader is directed to Sengupta et al. (2020) for the full details.

Table A1. Hyperparameters used in the vertical ozone BNN training

\begin{tabular}{l|c} 
Hyperparameter & Value \\
\hline No. of NNs in BNN ensemble & 48 \\
Hidden layer size & 500 \\
Learning rate & 0.0001 \\
Optimiser & Adam \\
No. epochs & 100000 \\
Batch size & 7500
\end{tabular}

Author contributions. MA developed the methodology with input from from US, PJY and SH. MA performed the production of the dataset and subsequent analysis. MA drafted the paper with input, comments and guidance from US, PJY and SH.

Competing interests. The authors declare no competing interests.

Acknowledgements. This work was supported by the Natural Environment Research Council (NERC grant reference no. NE/L002604/1), with Matt Amos's studentship through the Envision Doctoral Training Partnership. Ushnish Sengupta is an Early Stage Researcher within the MAGISTER consortium which receives funding from the European Union's Horizon 2020 research and innovation programme under the Marie Skłodowska-Curie grant agreement No 766264. Matt Amos and Paul J. Young are supported by the Data Science of the Natural Environment (DSNE) project, funded by the UK Engineering and Physical Sciences Research Council (EPSRC; grant no. EP/R01860X/1). Computationally this work used JASMIN, the UK collaborative data analysis facility, and was also supported with research credits provided by Google Cloud. We are extremely grateful for informative conversations with Birgit Hassler and Stefanie Kremser about the Bodeker Scientific dataset. For access to ozone datasets we would like to thank Bodeker Scientific, funded by the New Zealand Deep South National Science Challenge, for providing the combined NIWA-BS total column ozone database, the SWOOSH, SBUV and BASIC teams. We acknowledge the modelling groups for making their simulations available for this analysis, the joint WCRP SPARC-IGAC Chemistry-Climate Model Initiative (CCMI) for organising and coordinating the model data analysis activity, and the British Atmospheric Data Centre (BADC) for collecting and archiving the CCMI model output. We are also grateful for the NCEP Reanalysis Derived data provided by the NOAA/OAR/ESRL PSL, Boulder, Colorado, USA. The EMAC simulations have been performed at the German Climate Computing Center (DKRZ) through support from the Bundesministerium für Bildungund Forschung (BMBF). DKRZ and its scientific steering committee are gratefully acknowledged for providing the HPC and data archiving resources for this consortial project ESCiMo (Earth System Chemistry integrated Modelling). The CCSRNIES-MIROC3.2 model computations were performed on NEC-SX9/A(ECO) and NEC SX- 
ACE computers at the CGER and NIES, supported by the Environment Research and Technology Development Funds of the Ministry of the Environment, Japan (2-1303), and Environmental Restoration and Conservation Agency, Japan (2-1709). We are extremely grateful for the easy to use and well documented DLM code provided by Justin Alsing (Alsing and Smith, 2019). Finally, all model and observational analysis was performed using the python package iris (Met Office, 2010 - 2013). 
Alsing, J.: dlmmc: Dynamical linear model regression for atmospheric time-series analysis, Journal of Open Source Software, 4, 1157, https://doi.org/10.21105/joss.01157, 2019.

Alsing, J. and Ball, W.: BASIC composite ozone time-series data, Mendeley Data, v2., 2, https://doi.org/10.17632/2mgx2xzzpk, 2017.

Alsing, J. and Smith, A.: justinalsing/dlmmc: Second release, https://doi.org/10.5281/zenodo.2660704, 2019.

Amos, M.: mattramos/VertOzone-BNN: BNNOz Code Version for ESSD submission, https://doi.org/10.5281/zenodo.5606967, 2021.

Amos, M., Young, P. J., Hosking, J. S., Lamarque, J.-F., Abraham, N. L., Akiyoshi, H., Archibald, A. T., Bekki, S., Deushi, M., Jöckel, P., Kinnison, D., Kirner, O., Kunze, M., Marchand, M., Plummer, D. A., Saint-Martin, D., Sudo, K., Tilmes, S., and Yamashita, Y.: Projecting ozone hole recovery using an ensemble of chemistry-climate models weighted by model performance and independence, Atmospheric Chemistry and Physics, 20, 9961-9977, https://doi.org/10.5194/acp-20-9961-2020, 2020.

Amos, M., Sengupta, U., Hosking, J. S., and Young, P. J.: BNNOz - Infilled vertically resolved ozone dataset, https://doi.org/10.5281/zenodo.5603750, 2021.

Ball, W. T., Alsing, J., Mortlock, D. J., Rozanov, E. V., Tummon, F., and Haigh, J. D.: Reconciling differences in stratospheric ozone composites, Atmospheric Chemistry and Physics, 17, 12 269-12 302, https://doi.org/10.5194/acp-17-12269-2017, 2017.

Ball, W. T., Alsing, J., Mortlock, D. J., Staehelin, J., Haigh, J. D., Peter, T., Tummon, F., Stübi, R., Stenke, A., Anderson, J., Bourassa, A., Davis, S. M., Degenstein, D., Frith, S., Froidevaux, L., Roth, C., Sofieva, V., Wang, R., Wild, J., Yu, P., Ziemke, J. R., and Rozanov, E. V.: Evidence for a continuous decline in lower stratospheric ozone offsetting ozone layer recovery, Atmospheric Chemistry and Physics, 18, 1379-1394, https://doi.org/10.5194/acp-18-1379-2018, 2018.

Berlin, F. U.: The Quasi-Biennial-Oscillation (QBO) Data Series last accessed: 1 September 2021), https://www.geo.fu-berlin.de/en/met/ag/ strat/produkte/qbo/index.html, 2021.

Blunden, J. and Arndt, D. S.: State of the Climate in 2015, Bulletin of the American Meteorological Society, 97, Si-S275, https://doi.org/10.1175/2016BAMSStateoftheClimate.1, 2016.

Bodeker, G., Hassler, B., Young, P., and Portmann, R. W.: A vertically resolved, global, gap-free ozone database for assessing or constraining global climate model simulations, Earth System Science Data, 5, 31-43, https://doi.org/10.5194/essd-5-31-2013, 2013.

Bodeker, G. E., Nitzbon, J., Tradowsky, J. S., Kremser, S., Schwertheim, A., and Lewis, J.: A global total column ozone climate data record, Earth System Science Data Discussions, pp. 1-33, https://doi.org/10.5194/essd-13-3885-2021, 2020.

Bowman, K. P. and Krueger, A. J.: A global climatology of total ozone from the Nimbus 7 total ozone mapping spectrometer, Journal of Geophysical Research: Atmospheres, 90, 7967-7976, https://doi.org/10.1007/978-94-009-5313-0_74, 1985.

Braesicke, P., Neu, J., Fioletov, V., Godin-Beekmann, S., Hubert, D., Petropavlovskikh, I., Shiotani, M., and Sinnhuber, B.-M.: Update on Global ozone: past, present, and Future, in: Scientific Assessment of Ozone Depletion: 2018, Global Ozone Research and Monitoring Project-Report No. 58, WMO (World Meteorological Organization), Geneva, Switzerland, http://ozone.unep.org/science/assessment/sap, 2018.

Chipperfield, M. P., Bekki, S., Dhomse, S., Harris, N. R., Hassler, B., Hossaini, R., Steinbrecht, W., Thiéblemont, R., and Weber, M.: Detecting recovery of the stratospheric ozone layer, Nature, 549, 211, https://doi.org/10.1038/nature23681, 2017.

Cionni, I., Eyring, V., Lamarque, J.-F., Randel, W., Stevenson, D., Wu, F., Bodeker, G., Shepherd, T., Shindell, D., and Waugh, D.: Ozone database in support of CMIP5 simulations: results and corresponding radiative forcing, Atmospheric Chemistry and Physics, 11, 11 26711 292, https://doi.org/10.5194/acp-11-11267-2011, 2011. 
Courtier, P., Thépaut, J.-N., and Hollingsworth, A.: A strategy for operational implementation of 4D-Var, using an incremental approach, Quarterly Journal of the Royal Meteorological Society, 120, 1367-1387, https://doi.org/10.1002/qj.49712051912, 1994.

Davis, S. M., Rosenlof, K. H., Hassler, B., Hurst, D. F., Read, W. G., Vömel, H., Selkirk, H., Fujiwara, M., and Damadeo, R.: The Stratospheric Water and Ozone Satellite Homogenized (SWOOSH) database: a long-term database for climate studies, Earth system science data, 8, 461-490, https://doi.org/10.5194/essd-8-461-2016, 2016.

de Wit, T. D., Bruinsma, S., and Shibasaki, K.: Synoptic radio observations as proxies for upper atmosphere modelling, Journal of Space Weather and Space Climate, 4, A06, https://doi.org/10.1051/swsc/2014003, 2014.

Eyring, V., Chipperfield, M. P., Giorgetta, M. A., Kinnison, D. E., Manzini, E., Matthes, K., Newman, P. A., Pawson, S., Shepherd, T. G., and Waugh, D. W.: Overview of the new CCMVal reference and sensitivity simulations in support of upcoming ozone and climate assessments and the planned SPARC CCMVal report, SPARC Newsletter, 30, 20-26, http://oceanrep.geomar.de/15163/, 2008.

Fioletov, V. E., Labow, G., Evans, R., Hare, E. W., Köhler, U., McElroy, C. T., Miyagawa, K., Redondas, A., Savastiouk, V., Shalamyansky, A. M., Staehelin, J., Vanicek, K., and Weber, M.: Performance of the ground-based total ozone network assessed using satellite data, Journal of Geophysical Research: Atmospheres, 113, https://doi.org/10.1029/2008JD009809, 2008.

Froidevaux, L., Jiang, Y. B., Lambert, A., Livesey, N. J., Read, W. G., Waters, J. W., Browell, E. V., Hair, J. W., Avery, M. A., McGee, T. J., Twigg, L. W., Sumnicht, G. K., Jucks, K. W., Margitan, J. J., Sen, B., Stachnik, R. A., Toon, G. C., Bernath, P. F., Boone, C. D., Walker, K. A., Filipiak, M. J., Harwood, R. S., Fuller, R. A., Manney, G. L., Schwartz, M. J., Daffer, W. H., Drouin, B. J., Cofield, R. E., Cuddy, D. T., Jarnot, R. F., Knosp, B. W., Perun, V. S., Snyder, W. V., Stek, P. C., Thurstans, R. P., and Wagner, P. A.: Validation of aura microwave limb sounder stratospheric ozone measurements, Journal of Geophysical Research: Atmospheres, 113, https://doi.org/10.1029/2007JD008771, 2008

Gaudel, A., Cooper, O. R., Ancellet, G., Barret, B., Boynard, A., Burrows, J. P., Clerbaux, C., Coheur, P.-F., Cuesta, J., Cuevas, E., Doniki, S., Dufour, G., Ebojie, F., Foret, G., Garcia, O., Granados-Muñoz, M. J., Hannigan, J. W., Hase, F., Hassler, B., Huang, G., Hurtmans, D., Jaffe, D., Jones, N., Kalabokas, P., Kerridge, B., Kulawik, S., Latter, B., Leblanc, T., Le Flochmoën, E., Lin, W., Liu, J., Liu, X., Mahieu, E., McClure-Begley, A., Neu, J. L., Osman, M., Palm, M., Petetin, H., Petropavlovskikh, I., Querel, R., Rahpoe, N., Rozanov, A., Schultz, M. G., Schwab, J., Siddans, R., Smale, D., Steinbacher, M., Tanimoto, H., Tarasick, D. W., Thouret, V., Thompson, A. M., Trickl, T., Weatherhead, E., Wespes, C., Worden, H. M., Vigouroux, C., Xu, X., Zeng, G., and Ziemke, J.: Tropospheric Ozone Assessment Report: Present-day distribution and trends of tropospheric ozone relevant to climate and global atmospheric chemistry model evaluation, Elementa: Science of the Anthropocene, 6, https://doi.org/10.1525/elementa.291, 2018.

Heath, D., Krueger, A. J., Roeder, H., and Henderson, B.: The solar backscatter ultraviolet and total ozone mapping spectrometer (SBUV/TOMS) for Nimbus G, Optical Engineering, 14, 144 323, https://doi.org/10.1117/12.7971839, 1975.

Hersbach, H., Bell, B., Berrisford, P., Hirahara, S., Horányi, A., Muñoz-Sabater, J., Nicolas, J., Peubey, C., Radu, R., Schepers, D., Simmons, A., Soci, C., Abdalla, S., Abellan, X., Balsamo, G., Bechtold, P., Biavati, G., Bidlot, J., Bonavita, M., De Chiara, G., Dahlgren, P., Dee, D., Diamantakis, M., Dragani, R., Flemming, J., Forbes, R., Fuentes, M., Geer, A., Haimberger, L., Healy, S., Hogan, R. J., Hólm, E., Janisková, M., Keeley, S., Laloyaux, P., Lopez, P., Lupu, C., Radnoti, G., de Rosnay, P., Rozum, I., Vamborg, F., Villaume, S., and Thépaut, J.-N.: The ERA5 global reanalysis, 146, 1999-2049, https://doi.org/10.1002/qj.3803, 2020.

Ivy, D. J., Solomon, S., Calvo, N., and Thompson, D. W.: Observed connections of Arctic stratospheric ozone extremes to Northern Hemisphere surface climate, Environmental Research Letters, 12, 024 004, https://doi.org/10.1088/1748-9326/aa57a4, 2017.

Kalnay, E., Kanamitsu, M., Kistler, R., Collins, W., Deaven, D., Gandin, L., Iredell, M., Saha, S., White, G., Woollen, J., Zhu, Y., Chelliah, M., Ebisuzaki, W., Higgins, W., Janowiak, J., Mo, K. C., Ropelewski, C., Wang, J., Leetmaa, A., Reynolds, R., Jenne, R., and Joseph, D.: The 

0477(1996)077<0437:TNYRP>2.0.CO;2, 1996.

Knutti, R., Furrer, R., Tebaldi, C., Cermak, J., and Meehl, G. A.: Challenges in Combining Projections from Multiple Climate Models, Journal of Climate, 23, 2739-2758, https://doi.org/10.1175/2009JCLI3361.1, 2010.

Lamarque, J.-F., Shindell, D. T., Josse, B., Young, P. J., Cionni, I., Eyring, V., Bergmann, D., Cameron-Smith, P., Collins, W. J., Doherty, R., Dalsoren, S., Faluvegi, G., Folberth, G., Ghan, S. J., Horowitz, L. W., Lee, Y. H., MacKenzie, I. A., Nagashima, T., Naik, V., Plummer, D., Righi, M., Rumbold, S. T., Schulz, M., Skeie, R. B., Stevenson, D. S., Strode, S., Sudo, K., Szopa, S., Voulgarakis, A., and Zeng, G.: The Atmospheric Chemistry and Climate Model Intercomparison Project (ACCMIP): overview and description of models, simulations and climate diagnostics, Geoscientific Model Development, 6, 179-206, https://doi.org/doi.org/10.5194/gmd-6-179-2013, 2013.

Met Office: Iris: A Python package for analysing and visualising meteorological and oceanographic data sets, Exeter, Devon, v1.2 edn., http://scitools.org.uk/, 2010 - 2013.

Miller, A. J., Nagatani, R. M., Flynn, L. E., Kondragunta, S., Beach, E., Stolarski, R., McPeters, R. D., Bhartia, P. K., DeLand, M. T., Jackman, C. H., Wuebbles, D. J., Patten, K. O., and Cebula, R. P.: A cohesive total ozone data set from the SBUV(/2) satellite system, Journal of Geophysical Research: Atmospheres, 107, ACH 11-1-ACH 11-8, https://doi.org/10.1029/2001JD000853, 2002.

Morgenstern, O., Hegglin, M. I., Rozanov, E., O’Connor, F. M., Abraham, N. L., Akiyoshi, H., Archibald, A. T., Bekki, S., Butchart, N., Chipperfield, M. P., Deushi, M., Dhomse, S. S., Garcia, R. R., Hardiman, S. C., Horowitz, L. W., Jöckel, P., Josse, B., Kinnison, D., Lin, M., Mancini, E., Manyin, M. E., Marchand, M., Marécal, V., Michou, M., Oman, L. D., Pitari, G., Plummer, D. A., Revell, L. E., Saint-Martin, D., Schofield, R., Stenke, A., Stone, K., Sudo, K., Tanaka, T. Y., Tilmes, S., Yamashita, Y., Yoshida, K., and Zeng, G.: Review of the global models used within phase 1 of the Chemistry-Climate Model Initiative (CCMI), Geoscientific Model Development, 10, 639-671, https://doi.org/10.5194/gmd-10-639-2017, 2017.

Morgenstern, O., Stone, K. A., Schofield, R., Akiyoshi, H., Yamashita, Y., Kinnison, D. E., Garcia, R. R., Sudo, K., Plummer, D. A., Scinocca, J., Oman, L. D., Manyin, M. E., Zeng, G., Rozanov, E., Stenke, A., Revell, L. E., Pitari, G., Mancini, E., Di Genova, G., Visioni, D., Dhomse, S. S., and Chipperfield, M. P.: Ozone sensitivity to varying greenhouse gases and ozone-depleting substances in CCMI-1 simulations, Atmospheric Chemistry and Physics, 18, 1091-1114, https://doi.org/10.5194/acp-18-1091-2018, 2018.

NCAR: The Climate Data Guide: Multivariate ENSO Index last accessed: 1 September 2021), https://climatedataguide.ucar.edu/climate-data/ multivariate-enso-index, 2019.

Neal, R. M.: Bayesian learning for neural networks, vol. 118, Springer Science \& Business Media, https://doi.org/10.1007/978-1-4612-07450,2012 .

Newman, P., Daniel, J., Waugh, D., and Nash, E.: A new formulation of equivalent effective stratospheric chlorine (EESC), Atmospheric Chemistry and Physics, 7, 4537-4552, https://doi.org/10.5194/acp-7-4537-2007, 2007.

Newton, R., Vaughan, G., Hintsa, E., Filus, M. T., Pan, L. L., Honomichl, S., Atlas, E., Andrews, S. J., and Carpenter, L. J.: Observations of ozone-poor air in the tropical tropopause layer, Atmospheric Chemistry and Physics, 18, 5157-5171, https://doi.org/10.5194/acp-185157-2018, 2018.

Orbe, C., Plummer, D. A., Waugh, D. W., Yang, H., Jöckel, P., Kinnison, D. E., Josse, B., Marecal, V., Deushi, M., Abraham, N. L., Archibald, A. T., Chipperfield, M. P., Dhomse, S., Feng, W., and Bekki, S.: Description and Evaluation of the specified-dynamics experiment in the Chemistry-Climate Model Initiative, Atmospheric Chemistry and Physics, 20, 3809-3840, https://doi.org/10.5194/acp-20-3809-2020, 2020 . 
Pearce, T., Leibfried, F., and Brintrup, A.: Uncertainty in neural networks: Approximately bayesian ensembling, in: International conference on artificial intelligence and statistics, pp. 234-244, PMLR, https://proceedings.mlr.press/v108/pearce20a.html, 2020.

Petropavlovskikh, I., Godin-Beekmann, S., Hubert, D., Damadeo, R., Hassler, B., and Sofieva, V.: Report on Long-term Ozone Trends and Uncertainties in the Stratosphere, SPARC/IO3C/GAW, https://doi.org/10.17874/f899e57a20b, 2018.

Polvani, L. M., Abalos, M., Garcia, R., Kinnison, D., and Randel, W. J.: Significant weakening of Brewer-Dobson circulation trends over the 21st century as a consequence of the Montreal Protocol, Geophysical Research Letters, 45, 401-409, https://doi.org/10.1002/2017GL075345, 2018.

Randel, W. J. and Wu, F.: A stratospheric ozone trends data set for global modeling studies, Geophysical Research Letters, 26, 3089-3092, https://doi.org/10.1029/1999GL900615, 1999.

Randel, W. J. and Wu, F.: A stratospheric ozone profile data set for 1979-2005: Variability, trends, and comparisons with column ozone data, Journal of Geophysical Research: Atmospheres, 112, https://doi.org/10.1029/2006JD007339, 2007.

Reichler, T. and Kim, J.: How Well Do Coupled Models Simulate Today's Climate?, Bulletin of the American Meteorological Society, 89, 303-312, https://doi.org/10.1175/BAMS-89-3-303, 2008.

Rienecker, M. M., Suarez, M. J., Gelaro, R., Todling, R., Bacmeister, J., Liu, E., Bosilovich, M. G., Schubert, S. D., Takacs, L., Kim, G.-K., Bloom, S., Chen, J., Collins, D., Conaty, A., da Silva, A., Gu, W., Joiner, J., Koster, R. D., Lucchesi, R., Molod, A., Owens, T., Pawson, S., Pegion, P., Redder, C. R., Reichle, R., Robertson, F. R., Ruddick, A. G., Sienkiewicz, M., and Woollen, J.: MERRA: NASA's modern-era retrospective analysis for research and applications, Journal of climate, 24, 3624-3648, https://doi.org/10.1175/JCLI-D-11-00015.1, 2011.

Sengupta, U., Amos, M., Hosking, J. S., Rasmussen, C. E., Juniper, M., and Young, P. J.: Ensembling geophysical models with Bayesian neural networks, Advances in Neural Information Processing Systems, 33, https://papers.nips.cc/paper/2020/file/ 0d5501edb21a59a43435efa67f200828-Paper.pdf, 2020.

Sun, Z. and Archibald, A. T.: Multi-stage ensemble-learning-based model fusion for surface ozone simulations: A focus on CMIP6 models, Environmental Science and Ecotechnology, 8, 100 124, https://doi.org/10.1016/j.ese.2021.100124, 2021.

Tegtmeier, S., Hegglin, M. I., Anderson, J., Bourassa, A., Brohede, S., Degenstein, D., Froidevaux, L., Fuller, R., Funke, B., Gille, J., Jones, A., Kasai, Y., Krüger, K., Kyrölä, E., Lingenfelser, G., Lumpe, J., Nardi, B., Neu, J., Pendlebury, D., Remsberg, E., Rozanov, A., Smith, L., Toohey, M., Urban, J., von Clarmann, T., Walker, K. A., and Wang, R. H. J.: SPARC Data Initiative: A comparison of ozone climatologies from international satellite limb sounders, Journal of Geophysical Research: Atmospheres, 118, https://doi.org/10.1002/2013JD019877, 2013.

Thomason, L. W., Ernest, N., Millán, L., Rieger, L., Bourassa, A., Vernier, J.-P., Manney, G., Luo, B., Arfeuille, F., and Peter, T.: A global space-based stratospheric aerosol climatology: 1979-2016, Earth System Science Data, 10, 469-492, https://doi.org/10.5194/essd-10469-2018, 2018.

Viste, E., Korecha, D., and Sorteberg, A.: Recent drought and precipitation tendencies in Ethiopia, Theoretical and Applied Climatology, 112, 535-551, https://doi.org/10.1007/s00704-012-0746-3, 2013.

Waters, J., Froidevaux, L., Harwood, R., Jarnot, R., Pickett, H., Read, W., Siegel, P., Cofield, R., Filipiak, M., Flower, D., Holden, J., Lau, G., Livesey, N., Manney, G., Pumphrey, H., Santee, M., Wu, D., Cuddy, D., Lay, R., Loo, M., Perun, V., Schwartz, M., Stek, P., Thurstans, R., Boyles, M., Chandra, K., Chavez, M., Chen, G.-S., Chudasama, B., Dodge, R., Fuller, R., Girard, M., Jiang, J., Jiang, Y., Knosp, B., LaBelle, R., Lam, J., Lee, K., Miller, D., Oswald, J., Patel, N., Pukala, D., Quintero, O., Scaff, D., Van Snyder, W., Tope, M., Wagner, P., and Walch, M.: The Earth observing system microwave limb sounder (EOS MLS) on the aura Satellite, IEEE Transactions on Geoscience and Remote Sensing, 44, 1075-1092, https://doi.org/10.1109/TGRS.2006.873771, 2006. 
530 Witte, J. C., Thompson, A. M., Smit, H. G., Fujiwara, M., Posny, F., Coetzee, G. J., Northam, E. T., Johnson, B. J., Sterling, C. W., Mohamad, M., Ogino, S., Jordan, A., and da Silva, F. R.: First reprocessing of Southern Hemisphere ADditional OZonesondes (SHADOZ) profile records (1998-2015): 1. Methodology and evaluation, Journal of Geophysical Research: Atmospheres, 122, 66116636, https://doi.org/10.1002/2016JD026403, 2017.

WMO: Scientific Assessment of Ozone Depletion: 2018, Global Ozone Research and Monitoring Project-Report No. 58, WMO, Geneva, Switzerland, 2018. 